\title{
The long and successful journey of electrochemically active amino acids. From fundamental adsorption studies to potential surface engineering tools.
}

\author{
ANDRÉ H.B. DOURADO, FABIÁN C. PASTRIÁN and SUSANA I. CÓRDOBA DE TORRESI
}

Instituto de Química, Universidade de São Paulo, Av. Prof. Lineu Prestes, 748, 05508-000 São Paulo, SP, Brazil

Manuscript received June 6, 2017; accepted for publication on July 26, 2017

\begin{abstract}
Proteins have been the subject of electrochemical studies. It is possible to apply electrochemical techniques to obtain information about their structure due to the presence of five electroactive amino acids that can be oriented to the outside of the peptidic chain. These amino acids are L-Tryptophan (L-Trp), L-Tyrosine (L-Tyr), L-Histidine (L-His), L-Methionine (L-Met) and L-Cysteine (L-Cys); their electrochemical behavior being subject of extensive research, but it is still controversial. No spectroscopic investigations have been reported on L-Trp, and due to the short life time of the intermediates, ex situ techniques cannot be employed, leading to a never-ending discussion about possible intermediates. In the L-Tyr and L-His cases, spectroelectrochemical studies were performed and different intermediates were observed, suggesting that some intermediates may be observed under specific conditions, as proposed for L-Cys. This amino acid is the most interesting among the electroactive ones because of the presence of a thiol moiety at its side chain, leading to a wide range of oxidation states. It can adsorb onto surfaces of different crystallographic orientation in stereoselective conformation, modifying the surface for different applications.as a surface engineering tool since it plays the role of as an anchor for the growing of nanocrystals inside proteic templates.
\end{abstract}

Key words: protein electro-oxidation, electrochemical active amino acids, L-Cysteine, $\mathrm{SAM}, \mathrm{Cu}_{2} \mathrm{O}$, low index facets nanoparticles.

\section{INTRODUCTION}

It is well known that proteins are widely used in electrochemical devices such as glucose sensors that use glucose oxidase enzyme to react with sugar, making indirect measurements by the electrochemical quantification of hydrogen peroxide (Cunningham et al. 2010, Gerlach et

Correspondence to: Susana Ines Córdoba de Torresi

E-mail: storresi@iq.usp.br

* Contribution to the centenary of the Brazilian Academy of Sciences. al. 2010). But, it must be pointed out that not just enzymes but proteins in general have been the subject of electrochemical studies since the discovery of polarography, which dates from the 30s (Brdička 1933, Heyrovský and Babička 1930, Jurka 1939); the first published paper on electrochemistry behavior of proteins was by Heyrovsky (Heyrovský and Babička 1930). At the time, a reduction wave was observed when a proteic media (Heyrovský and Babička 1930) such as urine, blood or protein solutions was added to an 
ammonium chloride solution. The explanation for this fact was the complexation of the ammonium cations and the protein, which was attributed to the electroactive species responsible for the "protein waves". Three years later, the same group ( Brdička 1933) published a detailed paper showing that the addition of a metallic cation $\left(\mathrm{Co}^{2+}\right)$ in the solution produced the splitting of the "protein wave" into two regions, and this was observed for several proteic media even at very low concentration. Many amino acids were tested, and just in the case of L-cystine ( $\mathrm{L}^{-\mathrm{Cys}_{2}}$ ), a dimer of L-cysteine (L-Cys), the "wave" was observed, leading to the assumption of the existence of a catalytic effect of this amino acid on hydrogen reduction; $\mathrm{L}_{-} \mathrm{Cys}_{2}$ is very common in protein structures and is responsible for the "protein wave". In 1939, Jurka suggested that not just the dissulfate was catalyzing the reaction but it was also due to the adsorption of these groups onto Hg (Jurka 1939). This method became an electroanalytical tool for cancer diagnosis, and it is still used as the base for studies in this area (Minevich and Tur'yan 2013).

Previous examples show that protein electrochemistry is a subject that has merited attention since the beginning, and Jurka has noted that it can be used as a diagnostic tool (Jurka 1939), even if the protein does not present a redox catalytic site as an enzyme, a subject that became of interest during the 1970s (Paleček et al. 2015).

At present, electrochemistry is still a useful a tool for protein studies, and it was recently reviewed by Paleček et al. (2015). Electrochemistry can be used for biochemical applications, not only as a source of diagnosis but also for genomics, gliconomics and proteomics studies (Paleček et al. 2015). Some of these studies have used the option of adding an iron center or a biomolecule that already has one (as cytochrome C) to simplify the system in a way that would make it possible to analyze the influence of the environment on this electroactive group based on non-destructive analysis (Paleček et al. 2015).

In the same review by Paleček and coworkers (2015), as in other works (Enache and Oliveira-Brett 2013, 2017, Xu et al 2005), it is highlighted that there are only five electroactive amino acids, L-histidine (L-His), L-methionine (L-Met), L-tyrosine (L-Tyr), L-tryptophan (L-Trp) and L-Cys. Although there is no difference in electrochemical activity in the case of $\mathrm{L}$ or D-stereoisomer, in the present work, all amino acids are referred to as L-isomer since this is the one that is naturally observed.

The fact that only these five amino acids of the twenty-three natural ones are electroactive made possible the use of electrochemistry in proteomics; the oxidation of these molecules is observed in the same potential region and present the same voltammetric profile when tested free or linked in (poli)peptides (Enache et al. 2016, Enache and Oliveira-Brett 2013, 2017, Paleček et al. 2015) as shown in Figure 1.

The current intensity can provide information about the way in which these amino acids are available to the electrode surface, in other words, if they are exposed on the external face of the protein structure or buried in the internal part of the biomolecule, also indicating if the protein is in its natural state or desaturated. (Enache et al. 2016, Enache and Oliveira-Brett 2017).

Enache and co-workers published a series of papers on the application of voltammetric techniques for the investigation of the structure, aggregation and denaturation of amyloid- $\beta$ peptide studied for Alzheimer disease (Enache et al. 2016, Enache and Oliveira-Brett 2017). The authors first compared the voltammetric profiles on carbon-based solid electrodes with atomic force microscopy images, a well-established technique for these studies (Enache et al. 2016). The $\mathrm{j} / \mathrm{E}$ potentiodynamic profile showed - in the potential window where the free amino acids L-Tyr, L-His and L-Met oxidation 


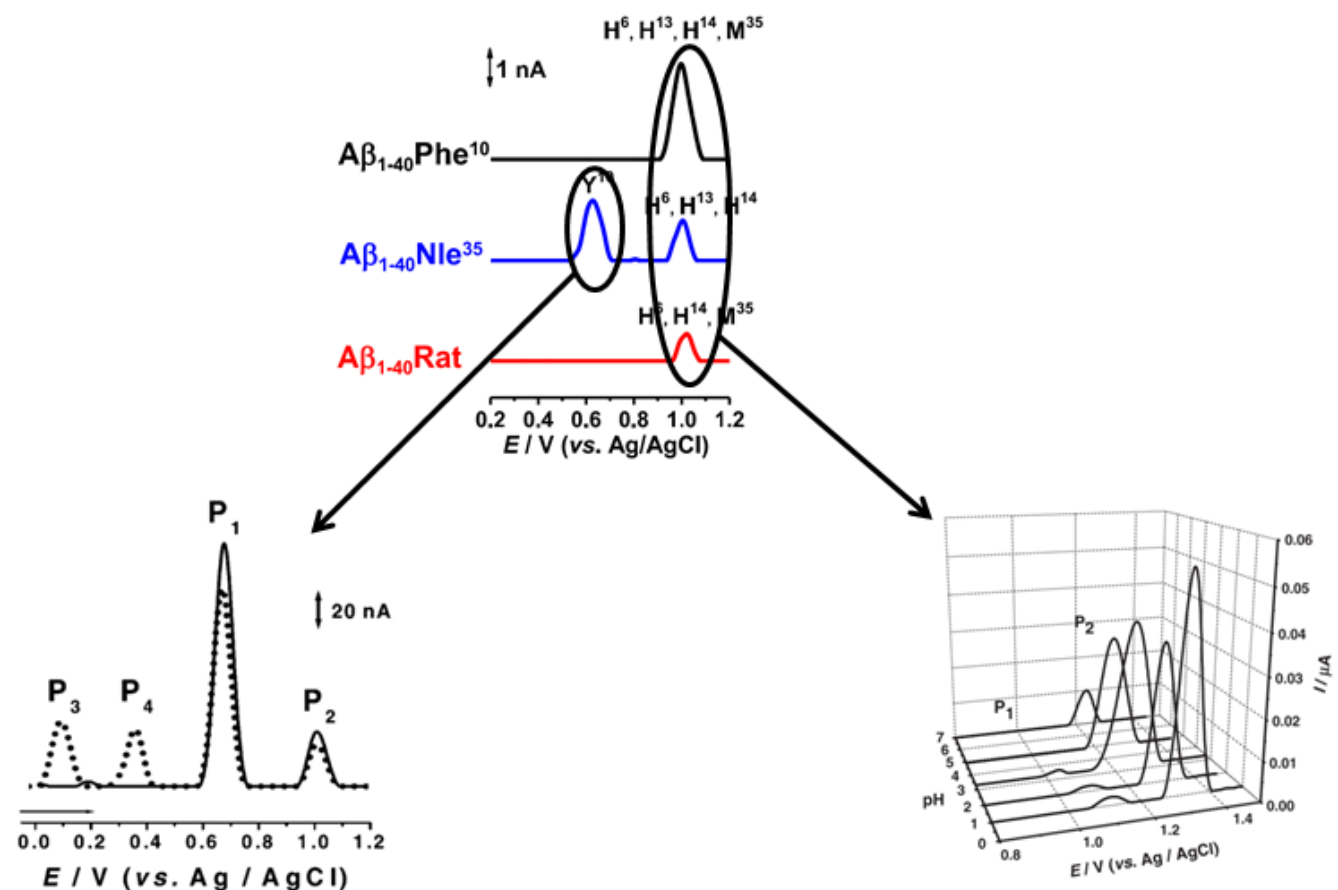

Figure 1 - Comparison between voltammograms of $\beta$-amloyd (top), adapted from (Enache et al. 2016) and the free amino acids L-Tyr (bottom, left), adapted from (Enache and Oliveira-Brett 2011a) and L-Met (bottom, right), adapted from (Enache and Oliveira-Brett 2011c), showing that the potential peak is the same for the bonded and free amino acid.

was expected - that amyloid- $\beta$ was electroactive (Figure 1) and not just that the response of the amino acids was independent on the bonding to a larger molecule but also that these residues were exposed to the electrode and thus the surface of the protein. This observation made it possible to infer about the variation of this availability after several modifications of the structure, such as mutations, inversion of the primary structure, denaturation and aggregation (Enache et al. 2016, Enache and Oliveira-Brett 2017). This study involved the understanding of the voltammetric behavior of the native/modified peptides and the increase or decrease of the current, indicating more or less accessibility to the amino acids and representing the modifications of the $\beta$-sheets and $\alpha$-helixes.

Since the potential of the free and linked amino acids is the same, it is possible to infer that the study of these molecules in solution is scientifically relevant due to the simplicity of working with a small molecule. The next sections of this review will expose the state of the art of the knowledge about the electrochemical behavior of these five amino acids.

\section{ELECTROCHEMICALLY ACTIVE AMINO ACIDS}

It was noted that the use of carbon-based electrodes should be preferential for amino acid electrochemical studies (Paleček et al. 2015) because metallic electrodes present voltammetric profiles in which oxides are formed and they are supposed to be occurring in the same potential range as the oxidation of the amino acids. But, in 1980, Malfoy and Reynaud (1980) compared metallic- and carbon-based electrodes, inferring that the oxidation mechanism of L-Trp does not change with the electrode and the oxidation of this species generates an adsorbed species that blocks the Au surface, shifting the formation of gold 
oxides to more positive potentials. The mechanism proposed (Malfoy and Reynaud 1980), Figure 2 , reaction 1.3, is not in full agreement with that recently proposed by Suprun et al. (2013) Figure 2, reaction 1.1 (Suprun et al. 2013); however, it can be assumed that the peaks observed on Au and glassy carbon electrodes are related to the same process, with the same response for scan and rotation rates concentration and $\mathrm{pH}$ variations (Malfoy and Reynaud 1980). Although the conclusion of Enache and Brett (Enache and Oliveira-Brett 2011a) was supported by the oxidation on carbon electrodes, Figure 2, reaction 1.4, since the electrochemical behavior was not as dependent on the electrode material (Malfoy and Reynaud 1980), the pathway should be the same for both situations. Enache and Brett presented a full study on the electrochemical oxidation of indol groups and derivate ones, as L-Trp (Enache and Oliveira-Brett 2011a), verifying the dependence of this mechanism on $\mathrm{pH}$, which made it possible to infer that the amount of protons and electrons is the same for both oxidation peaks, leading to the most complex proposed mechanism. Reaction 1.4 in Figure 2 can also lead to a diphenol in meta configuration (Enache and Oliveira-Brett 2011a).

Even with different products, the earlier work (Malfoy and Reynaud 1980) agrees with Suprun et al. and other published studies, Figure 2, reactions 1.1 and 1.2 (Cai et al. 1996, Suprun et al. 2013, Zhu et al.2014) in the amount of steps and oxidation peaks, which indicates that the chosen electrochemical technique (conventional voltammetry) might omit information and differential pulse voltammetry must be more suitable for these studies (Enache and Oliveira-Brett 2011a). None of the discussed papers presented spectroscopic data, which would address this controversy.

In the case of L-Tyr, a common point raised by most authors is that, no matter the electrode material, the phenol function is the one that is oxidized; (Cai et al. 1996, Enache and Oliveira-
Brett 2011b, Malfoy and Reynaud 1980, Suprun et al. 2013, Zhu et al. 2014) but the final product is controversial. Other works using spectroscopic techniques such as FTIR on metallic electrodes (Ogura et al. 1999, Zinola et al. 2005) assumed that the first observed oxidation is the descarboxilation of the molecule and, second, that of the amino group. Some authors assumed that the latter takes place simultaneously with the first one (Zinola et al. 2005), Figure 3, reaction 2.6. Most of the papers assuming the oxidation is related to the phenol group propose its oxidation to a ketone in a single step (Cai et al. 1996, Malfoy and Reynaud 1980, Suprun et al. 2013, Zhu et al. 2014), Figure 3, reactions 2.1, 2.2 and 2.4; however, some consider a polymerization a competing step (Malfoy and Reynaud 1980), Figure 3, reaction 2.3, while others propose that the oxidation of the phenol occurs in two monoeletronic steps, with an aromatic radical intermediate. This species, due to hybridization, can be oxidized in other carbon (meta to the alpha carbon $-\mathrm{C}_{\alpha}$ ), resulting in a molecule with two ketone groups, Figure 3, reaction 2.1 (Enache and Oliveira-Brett 2011b).

Reports in which spectroscopic techniques were employed showed that adsorption is important for this process, regardless of the acid, Figure 3, reaction 2.6 (Zinola et al. 2005), or alkaline electrolyte, Figure 3, reaction 2.5 (Ogura et al. 1999). In acidic media, the importance of adsorption due to changes in the voltammogram of polycrystalline and single crystal Pt electrodes was noted. The current intensity of the hydrogen under the potential deposition $\left(\mathrm{H}_{\mathrm{UPD}}\right)$ region is changed, indicating that the adsorbed sites are occupied by other species provoking the shift of the Pt oxide formation region (Zinola et al. 2005). The geometry of this adsorption can explain why the oxidation of the carboxylic group is facilitated, since the molecule should be laid down with - $\mathrm{COOH}$ close to the electrode surface, as well as the whole phenolic ring. After these oxidation steps, some 


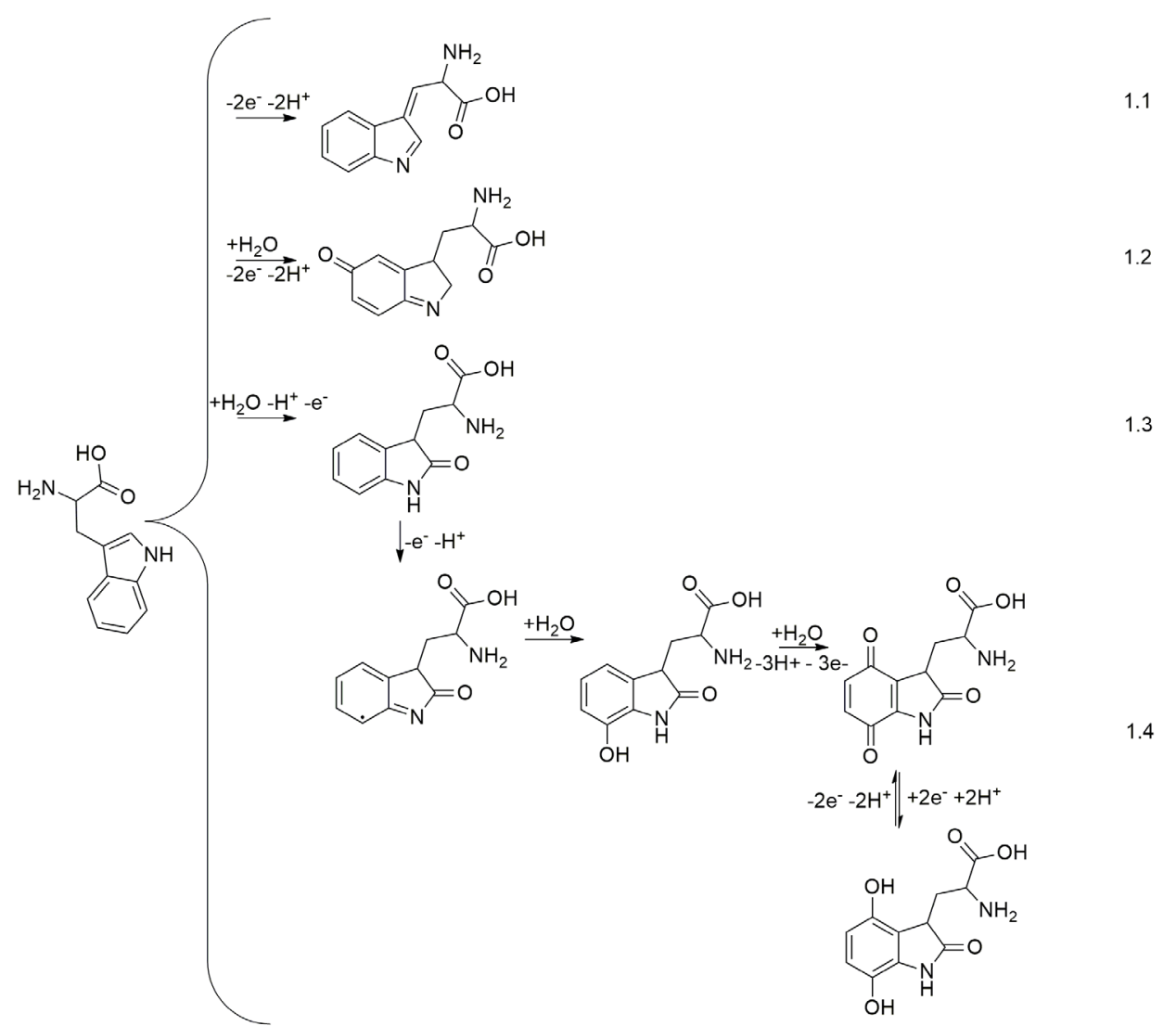

Figure 2 - Oxidation pathways of L-Trp as proposed in the literature by several authors. 1.1 (Suprun et al. 2013), 1.2 (Zhu et al. 2014), 1.3 (Malfoy and Reynaud 1980) and 1.4 (Enache and OliveiraBrett 2011a).

controversy appears among the authors. Ogura et al. (1999) assume that the final product would be phenol, while Zinola et al. (2005) propose a more complex pathway, in which the $\mathrm{C}_{\alpha}$ is oxidized to a ketone and its later oxidation generates a quinone, which is reoxidized to a para-diphenol (Zinola et al. 2005). It is possible that the oxidation process of this molecule differs depending on the electrode material, but one should keep in mind that in every case, the process presents many similarities (Malfoy and Reynaud 1980). The difference between the electrodes should be related to the increase/ decrease of probability of descarboxilation of the amino acid to occur.

L-His presents an imidazole ring in its side chain and despite earlier studies stating that it was not possible to observe specific oxidation of this amino acid, regardless of the electrode (Malfoy and Reynaud 1980), more recent studies on diamond and (Chen et al. 2008) and Pt electrodes (Ogura et al. 1999) show the opposite. The study of the behavior of this amino acid is important due to the possibility of using a L-His tag at the end of designed proteins to facilitate their isolation since its side chain adsorbs onto metallic electrodes (Ley et al. 2011, Ogura et al. 1999). The electrochemical behavior of this molecule, according to the literature (Chen et al. 2008), is still not clear; it seems to be more sensitive to the electrode nature than other amino acids previously discussed. On ceramic electrodes, the oxidation mechanism seems to follow a path involving the electrochemical polymerization generating an insulating film, Figure 4, reaction 3.2. The mechanism based on this film, characterized 


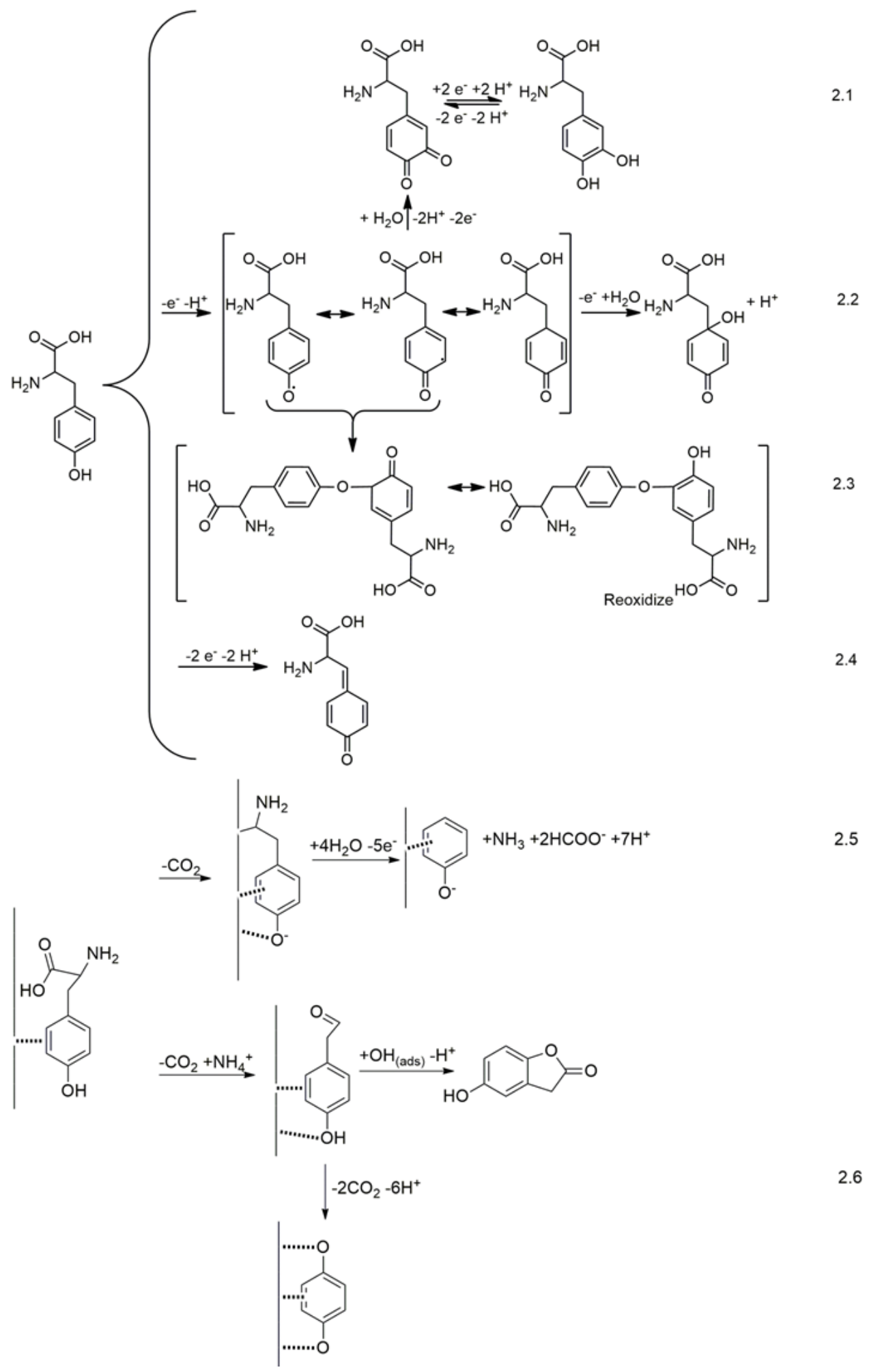

Figure 3 - Oxidation pathways proposed for L-Tyr in the literature by 2.1 (Enache and Oliveira-Brett 2011b), 2.2 and .3 (Malfoy and Reynaud 1980), 2.4 (Suprun et al. 2013), 2.5 (Ogura et al. 1999) and 2.5 (Zinola et al. 2005). 
by ex situ techniques (Chen et al. 2008), suggests that oxidant species were formed by the water and sulfate oxidation, and these are responsible for oxidizing the imidazole ring leading to a radical species, which should be responsible for the propagation step of the polymerization.

On the other hand, on metallic electrodes, Figure 4, reaction 3.1 (Ogura et al. 1999), the molecule will adsorb due to the side chain and carboxylic acid, and it will be electrochemically oxidized to generate $\mathrm{CO}_{2}$, formic acid, ammonia and a free imidazole. These steps are multielectronic, proving that the possibility of a more detailed mechanism, as suggested by Chen et al. (2008), is truly possible.

The other electroactive amino acids are L-Cys and L-Met, which, according to previous studies (Enache and Oliveira-Brett 2011c, Reynaud et al. 1980), should follow the same mechanism after L-Met loses the methyl group bonded to the S atom. Due to this and the high importance of their oxidation pathways in biological systems (Jacob et al. 2003), they will be discussed in more detail in the next section.

\section{SULFUR AMINO ACIDS}

\section{OXIDATION}

As stated in the literature (Jacob et al. 2003), the oxidation state of the sulfur function of L-Cys and L-Met can affect the activity of a large range of enzymes and also those that present L-Cys at the active site, which present a larger range of oxidation states. This kind of process, involving the oxidation of these sulfur-containing molecules, are a rare example of reversibility in biochemical redox reactions (Enache and Oliveira-Brett 2011c, Jacob et al. 2003).

With this in mind, it is interesting to investigate the electrochemical activity of these two amino acids in more detail to obtain information about the oxidation-reduction on electrodes and the redox behavior in chemical/biochemical conditions. Some studies suggested that the oxidation mechanisms of L-Met and L-Cys on different electrodes are very close (Enache and Oliveira-Brett 2011c, Reynaud et al. 1980) since the adsorption of L-Met is believed to be followed by the break of the $\mathrm{S}-\mathrm{CH}_{3}$ bond, generating a thiyl radical - the same observed with thiols - that adsorbs by the oxidation and break of the S-H bond. Because of this, L-Cys is a very interesting molecule to study, demonstrated by the larger amount of studies in the literature (Dourado et al. 2016, 2017, Enache and Oliveira-Brett 2011c, Feliciano-Ramos et al. 2010, Pradac and Koryta 1968, Reynaud et al. 1980, Samec et al. 1975).

As noted in the first section of this review, L-Cys was mentioned in the first study of the electrochemistry of proteins as being the reason for the "protein wave" observed in the polarograms (Brdička 1933, Heyrovský and Babička 1930, Jurka 1939) related to the redox pair L-Cys $/$ L-Cys in the reduction process (Jurka 1939). But since the use of $\mathrm{Hg}$ electrodes is not common at present, it is necessary for the other electroactive amino acids to evaluate the electrochemical behavior of this molecule on solid electrodes.

The study of the electrochemical behavior of L-Cys on solid electrodes started in the 60s, with Davis and Bianco's work followed by the series published by Pardac and Koryta's group (Davis and Bianco 1966, Koryta and Pradac 1968a, b, Pradac and Koryta 1968, Samec et al. 1975). In these reports, metallic electrodes were used, and a parallel was traced between the electrochemical behavior of thiols and L-Cys (Davis and Bianco 1966), and a mechanism was proposed considering an adsorption step followed by the oxidation of the adsorbed species, Figure 5, reactions 4.1 and 4.2. As multielectronic steps are not common, the oxidation is usually described as a mechanism consisting of monoeletronic steps. Further work was done to study the process, and by using electrochemical techniques, an intermediate step was suggested, 


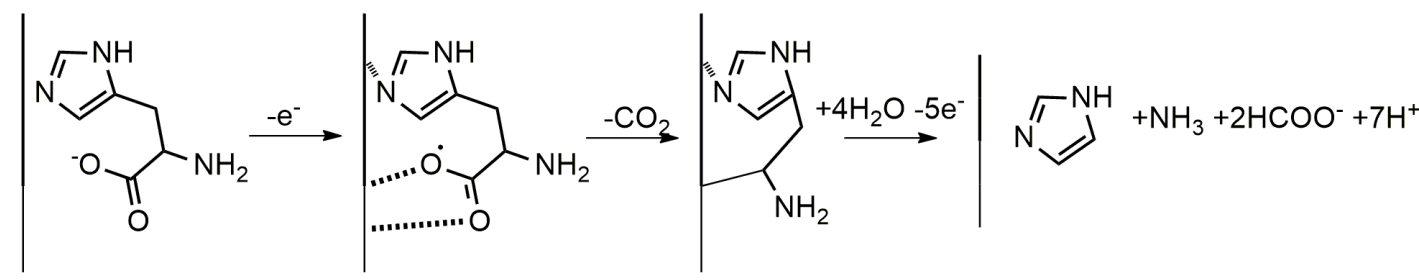

$\mathrm{BDD}+\mathrm{H}_{2} \mathrm{O} / \mathrm{SO}_{4}{ }^{2-} \stackrel{-\mathrm{e}^{-}}{\longrightarrow} \mathrm{OH} / \mathrm{S}_{2} \mathrm{O}_{8}^{2-}+\mathrm{BDD}$

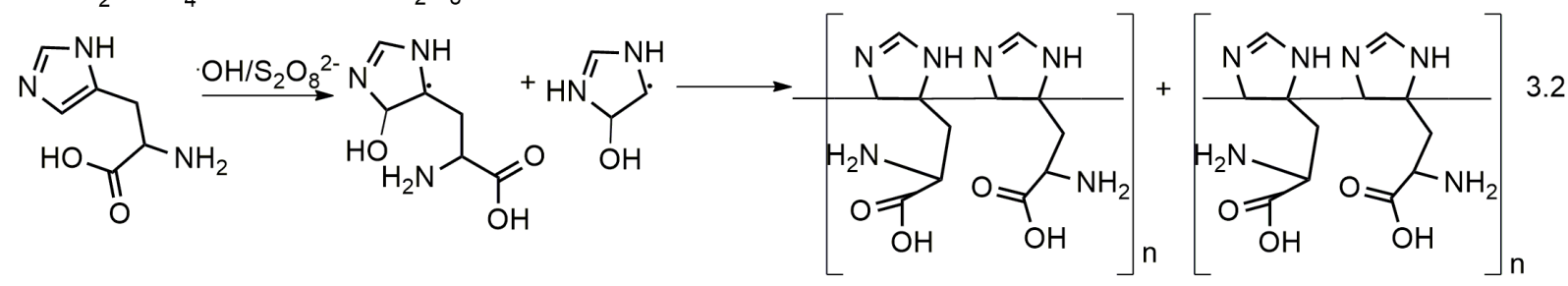

Figure 4 - Oxidation pathways proposed for L-His oxidation onto metallic electrodes by 3.1 (Ogura et al. 1999) and 3.2 (Chen et al. 2008).

in which is proposed the generation of another adsorbed species, an adsorbed sulfone ( $\left.\mathrm{R}-\mathrm{SO}_{2}-\mathrm{M}\right)$ that is oxidized to sulfonic acid by a single electron transfer, Figure 5, reaction 4.3 (Pradac and Koryta 1968). In the same work, the authors suggest that this is not the final mechanism because of the fourelectrons step, but they also pointed out that with that technology, it was not possible to go further. This first study was carried out on Pt (Pradac and Koryta 1968), and later the same group presented a work on Au (Koryta and Pradac 1968a) in addition to a third one, in which they compare the reaction between both electrodes (Koryta and Pradac 1968b). In the first work, the oxidation is probably due to a Frumkin-Podlovchenko mechanism (Pradac and Koryta 1968), and this proposition is better explained for the Au electrode (Koryta and Pradac 1968a); they suggest that the adsorbed hydroxide generated by the electrode surface oxidation oxidizes the adsorbed species. Finally, as noted later by Reynaud and co-workers (1980), the pathway for both electrodes should be similar (Koryta and Pradac 1968b).

Despite this point of convergence, Reynaud et al. (1980), Koryta and Pradac (1968a, b, Pradac and Koryta 1968) disagree about the possible oxidation mechanism. The first group performed spectroscopic measurements by XPS to investigate the oxidation state of the adsorbed sulfur atom; a complex mechanism is proposed whereby the adsorbed species is combined, generating L-Cys and this species absorbing by losing one of the R chains (Reynaud et al. 1980). This kind of mechanism was only proposed in this study, and the probability of breaking an S-S bond should be higher than for a $\mathrm{C}-\mathrm{S}$ one; so, an adsorption step where the former bond is broken should be more suitable, as suggested by many other works (Dourado et al. 2017, Hager and Brolo 2003, Watanabe and Maeda 1989). The literature about electrochemical dessorption of thiols (Widrig et al. 1991, Zhong and Porter 1997, Zhong et al. 1997) does not present much information on the mechanism since currently only the regeneration of the S-S bond is considered, and if the oxidation is analyzed, not many advances apart from a multielectronic mechanism were related. A recent work (Dourado et al. 2016) showed that not just the oxidation of the adsorbed species is rate limited by a desorption step, but also this desorption is observed at less positive potentials than the oxidation of the Pt substrate, indicating that the mechanism proposed by Pradac and Koryta (1968, Koryta and Pardac 1968a) can be questioned. 


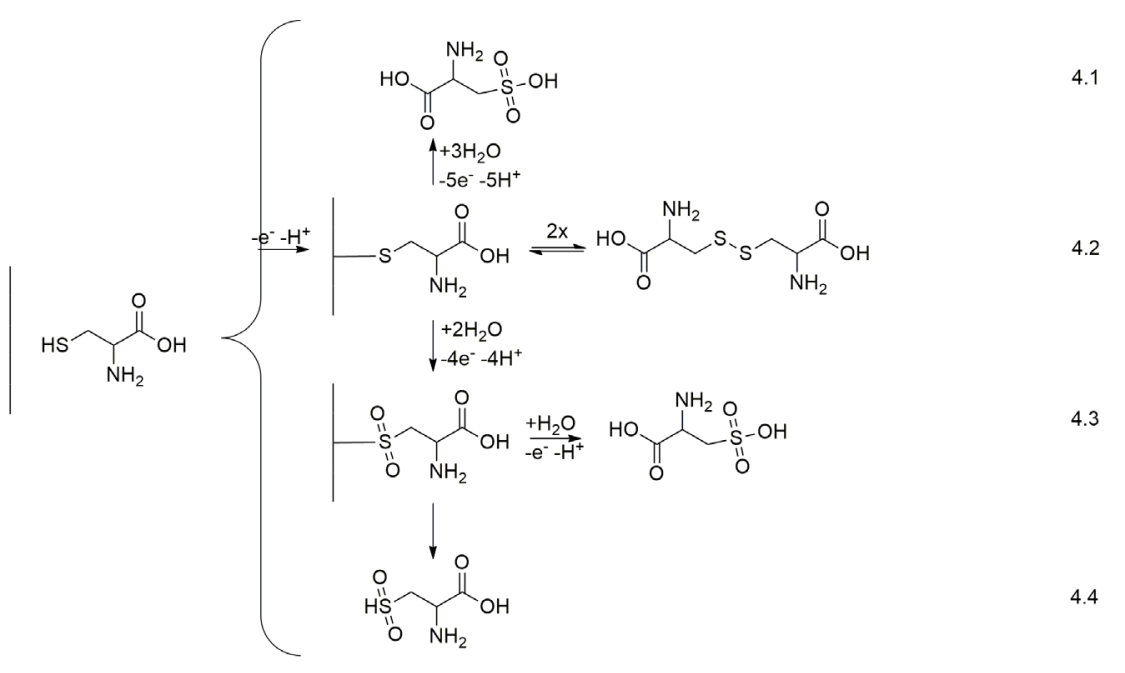

Figure 5 - Oxidation pathways proposed in the literature for the oxidation of L-Cys by 4.1 and .2 (Davis and Bianco 1966), 4.3 (Pradac and Koryta 1968) and 4.4 (FelicianoRamos et al. 2010).

Other kinds of electrodes were also used in recent years, such as Pd (Feliciano-Ramos et al. 2010), Ag (Hager and Brolo 2003, Santos et al. 2007, 2008) and diamond (Enache and OliveiraBrett 2011c). Studies performed with Ag did not clarify about the oxidation of the molecule mainly because the potential range is not very large, so that they are mainly focused on adsorption and reductive desorption (Hager and Brolo 2003, Santos et al. 2007, 2008). In Feliciano-Ramos et al. (2010), a multielectronic step is proposed, Figure 5 , reaction 4.4 , but the work performed on diamond electrodes proposed different oxidation species, studying different sulfur-containing amino acids for better understanding their bio-redox activity, which is of vital importance (Jacob et al. 2003). The authors investigated organic functions such as sulfinic acid, which are observed in vivo but never cited as intermediates of the electro-oxidation of L-Cys (Enache and Oliveira-Brett 2011c).

Due to thecontroversy about the electrochemical behavior of these amino acids, it is possible to observe that not much scientific progress about the oxidation mechanism was obtained from Reynaud et al. (1980) until the Enache and Oliveira-Brett (2011c) investigation, but major efforts were made to develop a possible quantification of L-Cys (Johll et al. 1997, Popović and Johnson 1998, Tudos et al. 1995, Vandeberg and Johnson 1993). Some of the cited works tried to obtain more detailed information about the mechanism by using electrochemical quartz crystal microbalance (EQCM) and ex situ spectroscopy (Tudos et al. 1995), but the complex behavior of this reaction made the EQCM study difficult since oxide generation and solvent degradation were observed in the same region as the adsorbed species. Ex situ analysis, after an exhaustive oxidation, detected just two principal products, L-Cys ${ }_{2}$ and sulfonic acid species, Figure 5, reactions 4.1 and 4.2. Hydrodynamic techniques were also used (Popović and Johnson 1998, Tudos et al. 1995), and again, not much new and relevant information was obtained. Nevertheless, pulsed amperometric techniques (Johll et al. 1997) present good reproducibility, sensitivity and detection limits and were selected by Johnson's group for developing an amino acid analyzer, in which an HPLC column is coupled with an electrochemical detector (Vandeberg and Johnson 1993); there has been a great deal of interest in this piece of equipment in biochemical structural studies. 
Recently, Dourado et al. (2017) studied the electrochemical oxidation of L-Cys and $\mathrm{L}-\mathrm{Cys}_{2}$ by infrared reflection absorption spectroscopy (IRRAS) in parallel with DFT calculations to predict the possible structures of the intermediates and the theoretical IR spectra. In this work, IRRAS spectra obtained at different applied potentials made it possible to detect intermediates that were not very common in the literature and others that were never suggested, Figure 6.

The DFT calculations made it possible to investigate the stability of those proposed molecules and to predict their spectra, corroborating the mechanistic suggestion. Some of the oxidized species that are not adsorbed (sulfinic acid) were observed at potentials more positives than $0.70 \mathrm{~V}$ (vs. $\mathrm{Ag}|\mathrm{AgCl}| \mathrm{KCl}_{\text {sat }}$ ), as suggested in a previous publication (Dourado et al. 2016) that proposed that the oxidative desorption took place in this region. The oxidation by the chemical reaction with the surface oxides (Koryta and Pradac 1968a, Pradac and Koryta 1968) would also explain the oxidation, but the mechanism should generate more oxidized species, being necessary to reduce the oxide back to Pt. So, spectroscopic data also suggest that direct oxidation of the adsorbed species is possible as well as generation of a wide range of intermediates, depending on $\mathrm{pH}$ (Dourado et al. 2017). Another aspect studied was the side reaction of the descarboxilation of the adsorbed species; this was a point not considered in any other work dealing with the electrooxidation of L-Cys but treated as being of high importance for L-Tyr (Ogura et al. 1999, Zinola et al. 2005) and L-His (Ogura et al. 1999). This kind of reaction could be related to a Kolbe Mechanism (Vijh and Conway 1967, Wang et al. 2015), but this kind of behavior should be more expressed in alkaline media due to the higher reactivity of the deprotonated carboxyl; but interestingly, in acid media $(\mathrm{pH} 0)$, this reaction was more pronounced (Dourado et al. 2017). This fact was explained by the structure of the first adsorbed species, which were different from those reported for Au (Bieri and Bürgi 2005, Di Felice et al. 2003, Di Felice and Selloni 2004) and Ag (Brolo et al. 2002, Luque et al. 2012, Santos et al. 2007, 2008), meaning that the carboxyl was away from the surface for $\mathrm{Au}$ and $\mathrm{Ag}$ at lower $\mathrm{pH}$ values and closer in alkaline media. The fact that on $\mathrm{Pt}$ the position of the carboxyl is the opposite can be due to its high affinity to $\mathrm{H}$ adsorption and catalysis, being the only one among the three electrodes to present a $\mathrm{H}_{\mathrm{UPD}}$ region. Because of this, the adsorbed L-Cys with the protonated carboxyl closer to the surface that is involved in some kind of $\mathrm{H}$ bond between the molecule and the surface would favor the Kolbe reaction instead of the deprotonated one away from the surface.

The fact that the adsorbed structure is of crucial importance even for side reactions at very positive potentials highlights the importance of investigating this phenomenon.

\section{ADSORPTION}

As pointed out in an earlier work (Dourado et al. 2017), the adsorption of L-Cys is a key point for understanding certain side reactions, such as the Kolbe descarboxylation (Vijh and Conway 1967, Wang et al. 2015). Also, the formation of a film at the surface is an example of a self-assembling monolayer (SAMs), which was reviewed recently for different amino acids on metallic surfaces with the expectation that different effects would take place on the oxides (Costa et al. 2015). Thiols are molecules that are very well known for this purpose (Eu and Paik 1999, Paik et al. 2000), and as recently reviewed (Chi et al. 2017), the bonding between the thiol and the metallic electrode can be explained by an acidic-basic reaction since metallic materials are strong Lewis acid species and thiols, especially thiolates, strong nucleophiles. But this $\mathrm{S}-\mathrm{M}$ bond is so strong in Au surfaces, qualitatively compared with $\mathrm{Pt}$, because $\mathrm{Au}$ is a much softer acid 


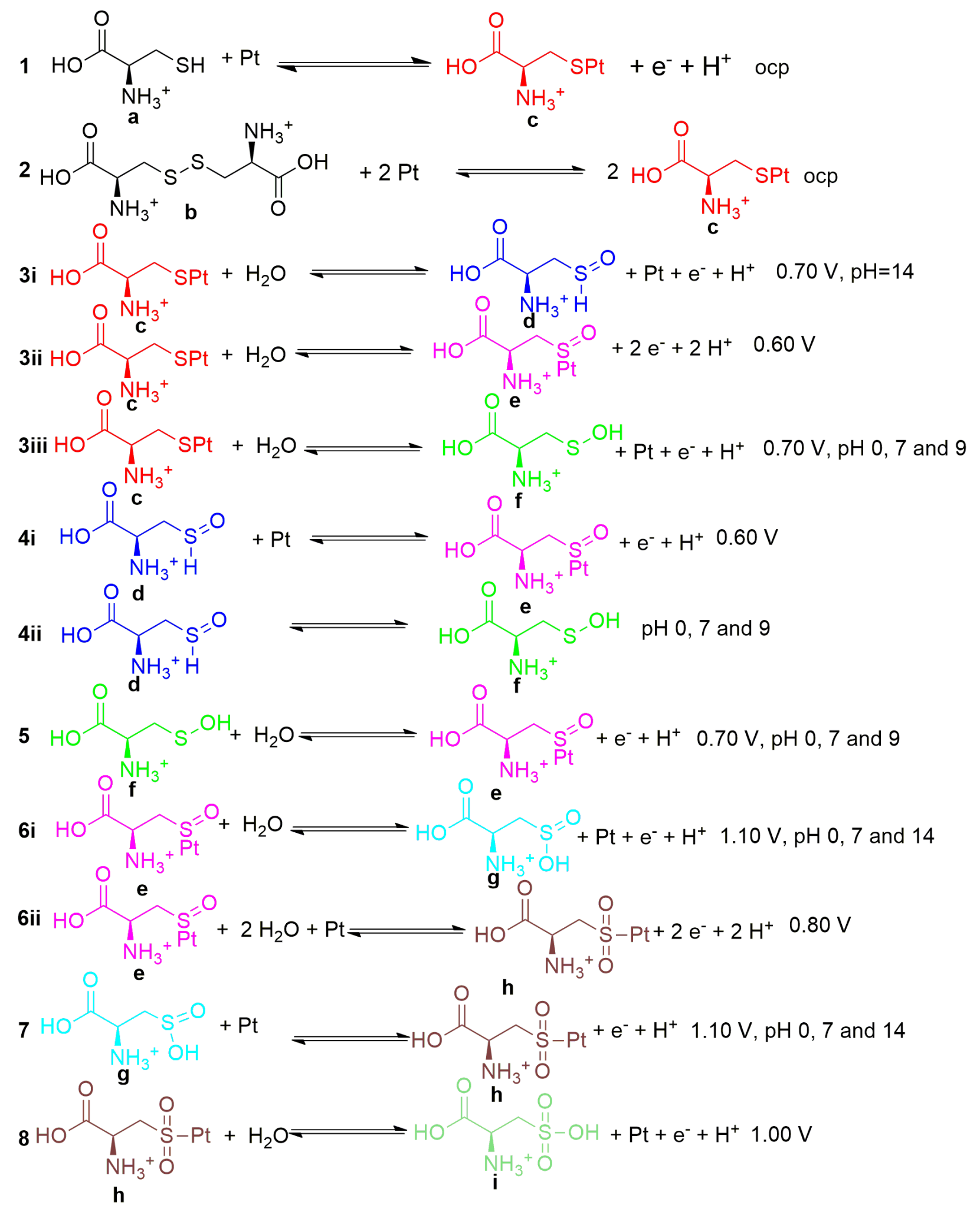

Figure 6 - Recently proposed a pathway for L-Cys oxidation (Dourado et al. 2017). 
than Pt, and thiol(ate) is a soft basic species (Chi et al. 2017, Pearson 1963, Zhou et al. 2004). Also, the $\mathrm{S}-\mathrm{Au}$ bond for adsorbed thiols is suggested to be as strong as the Au-Au bond (Häkkinen 2012). The nature of this bond is subject to extensive studies, as stated not just by this work but also other recent publications (Reimers et al. 2016). Gold and also other noble metals present a high number of possible oxidation numbers. Gold can be found in oxidation states from I to VI in nanoparticle chemistry (Häkkinen 2012), but the most important ones are I and 0 , after the bond with thiols (Reimers et al. 2016). The adsorption step, shown in Figure 5 and 6 , is an electrochemical one, so the thiol is oxidized to a thiyl adsorbed radical, and the metal still remains at 0 oxidation state $(\mathrm{Au}(0)-\mathrm{S})$, with a higher contribution of $\mathrm{Au} d$ orbitals for the $\mathrm{Au}-\mathrm{S}$ formation (Reimers et al. 2016). For many years, the reaction that was believed to be happening was not this one since the Au-S bond was believed to present a more ionic nature, being a $\mathrm{Au}(\mathrm{I})$-thiolate $\left(\mathrm{Au}(\mathrm{I})-\mathrm{S}^{-}\right)$bond, in which the oxidized species should be the Au atom (Chi et al. 2017) and the $\mathrm{Au}$ $s$ orbital should be the one with higher contribution to the Au-S system. The differences between these two bonds may be the reason why some conditions generate a thiol SAM onto $\mathrm{Au}$ or a $\mathrm{Au}-\mathrm{S}$ thin film (Reimers et al. 2016).

The covalent bond $\mathrm{Au}(0)$-thiyl is observed when the adsorbed film is stable and a SAM is formed. DFT calculations predict the possibility of a small flux charge from $\mathrm{Au}$ to alkylthiol, and some XPS measurements observed $\mathrm{Au}(0)$ on the surfaces when the thiol SAM is formed, which was also observed for uncharged sulfur layers (Reimers et al. 2016). The hydrogen bond network observed in the case of L-Cys adsorption (Brolo et al. 2002, Hager and Brolo 2003) can be the reason for the stabilization of the SAM, contributing to the $\mathrm{Au}(0)$-thyil system, which stabilizes and protects the surface, to the detriment of the $\mathrm{Au}(\mathrm{I})$-thiolate one, which contributes to the dissolution of the surface (Chi et al. 2017, Reimers et al. 2016). This fact can be the reason why at $\mathrm{pH} 14$ the adsorption of L-Cys onto Pt does not occur (Dourado et al. 2017); the charged molecule does not favor the formation of a Metal-S bond with high covalent contribution, providing a more instable system. The carbonic chain of the thiol molecule provides higher differences between HOMO and LUMO (Häkkinen 2012). Also, the nature of the metal affects the level of covalency of the bond, being less covalent in the case of $\mathrm{Cu}$ and the most in the case of Au (Häkkinen 2012, Reimers et al. 2016), which can be understood in the sense of "hard" and "soft" acids (Pearson 1963). Since Au is "softer" than $\mathrm{Pt}$, the ionic contribution on the Pt-S bond can be expected to be higher. The ionic character of the bond can be controlled by the stabilization of the SAM, as the lateral interaction of the adsorbed species, since these two states are in equilibrium (Chi et al. 2017).

The nature of this bond was studied using AFM techniques (Xue et al. 2014) and DFT calculations (Tielens and Santos 2010). AFM experiments evaluated the importance of the experimental conditions on the bonding strength of the thiol to the surface since many disagreements among authors in the literature are explained by differences in the adsorption $\mathrm{pH}$, oxidized/reduced $\mathrm{Au}$ surface, exposure time and/or isolated/SAM differences (Xue et al. 2014). Xue et al. (2014) observed a stronger interaction between $\mathrm{Au}$ and $\mathrm{S}$ at pH 8 due to increasing alkalinity or nucleophilicity, similar to L-Cys on Pt (Dourado et al. 2017). But, taking into account the equilibrium between covalent $(\mathrm{Au}(0)$-thiyl) and ionic ( $\mathrm{Au}(\mathrm{I})$-thiolate) (Chi et al. 2017, Reimers et al. 2016) and the observation that oxidized surfaces also presented a stronger bond (Xue et al. 2014), the control of the $\mathrm{pH}$ and the oxidation state of the surfaces shift this equilibrium to a stronger association. Other authors (Ron and Rubinstein 1998) who compared the SAM process on electrochemically controlled 


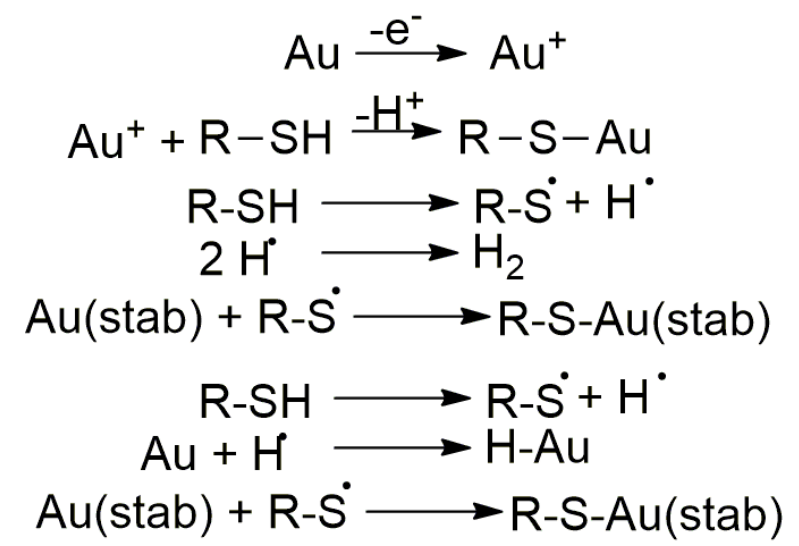

Figure 7 - Pathways proposed to thiol adsorption 6.1 by (Ron and Rubinstein 1998)measurement of the current corresponding to ethanol oxidation at the applied potential provides a convenient means for real-time monitoring of the self-assembly (SA and 6.2 (Tielens and Santos 2010).

surfaces arrived at the same conclusions. The oxidized $\mathrm{Au}$ presented a faster and more oriented SAM than the typical protocols, which demand up to $24 \mathrm{~h}$ for modification. The authors justified this improvement by a mechanism, Figure 7 , reaction 6.1, in which $\mathrm{Au}(0)$ was oxidized to $\mathrm{Au}(\mathrm{I})$ and then reacted with the thiol (Ron and Rubinstein 1998) probably forming a $\mathrm{Au}(\mathrm{I})$-thiolate species.

The reaction time, as mentioned, was studied by electrochemical methods (Ron and Rubinstein 1998) and at open circuit conditions, (Xue et al. 2014) for an individual molecule, and $3 \mathrm{~s}$ was enough for the reaction to be completed. A large difference was observed between the single molecule and the SAM experiment. A molecule involved in a SAM presents lower bond strength (Xue et al. 2014), and after $0.5 \mathrm{~h}$ of reaction, no differences in the values were observed. Also, the higher values of bond strength were, again, observed when thiolates and oxidized surfaces were used, but when the SAM was allowed to attempt 5 days, the bonding force was in agreement with the single molecule-reduced surface system. The lower values for the SAM were explained by the higher covalency of the bond, suggesting a $\mathrm{Au}(0)$-thiyl system. This result could suggest that the organic film that is formed over the Au surface provides the conditions to shift the equilibrium to this species.

Theoretical calculations (Di Felice et al. 2003, Di Felice and Selloni 2004, Tielens and Santos 2010) suggested that the geometry of the Au-S bond is in a bridge configuration, meaning that each $\mathrm{S}$ atom is bonded to two $\mathrm{Au}$ atoms, Figure 8. Also, Tielens and Santos (2010) suggested that this geometry and the organization of the carbonic chain presented no differences between an isolated molecule and a SAM, in disagreement to that proposed by some experimental results (Ron and Rubinstein 1998).

Nevertheless, the calculations also predicted that the bonding of a thiol to a Au surface affects the surface, provoking wave configuration and affecting the Au-Au bond around the Au-S (Tielens and Santos 2010). AFM-based measurements were able to verify this since the pulling of a thiol was enough to take some Au atoms together (Xue et al. 2014). The calculations were also able to suggest that the energetic pathway for a SAM formation is more favorable if the $\mathrm{S}-\mathrm{H}$ bond of the thiol group was homolitically broken and before the formation of the S-Au bond, Figure 7, reactions 6.2 and 6.3; in other words, if the pathway was followed by a bond breaking followed by a bond formation instead of a simultaneous reaction (Tielens and Santos 2010).

The proprieties of the Au-S system were also studied by scanning tunneling microscopy (STM) (Kühnle et al. 2002, Nazmutdinov et al. 2006, Zhang et al. 2005, 2006) on single crystal electrodes (Wackerbarth et al. 2004, Zhang et al. 2011). The 2D crystallography of the SAM formed on $\mathrm{Au}$ electrodes can be controlled by the $\mathrm{pH}$, electrolyte concentration and applied electrochemical potential. By STM, it was also possible to demonstrate that on an $\mathrm{Au}$ (111) surface, two thiols adsorb onto the same Au adatom. This fact is very interesting since the same $\mathrm{Au}$ atom is bonded with two thiolate/thiyl species and those bonded in a bridge geometry to two Au atoms, generating two possible enantiomeric 
surface complexes, as shown at the top of Figure 9 (Häkkinen 2012). When molecules that are already enantiomeric compounds are used, such as an amino acid, it is possible to lead to a higher level of enantiomericity. Some works can be found in the literature (Kühnle et al. 2002, 2003, 2006a, b) using $\mathrm{Au}$ (111) and Cys in both $\mathrm{L}$ and $\mathrm{D}$ forms, as shown at the bottom of Figure 9. These authors verified that Cys preferentially adsorbs around the [1-10] direction, which could be interpreted as an edge on the surface, as it was represented. The preferential bridge geometry for adsorption, shown in many cases on $\mathrm{Au}$ (Chi et al. 2017, Di Felice et al. 2003, Di Felice and Selloni 2004, Häkkinen 2012), Ag (Luque et al. 2012, Santos et al. 2008) and Pt (Dourado et al. 2017) as a key factor for the formation of stereoisomers on the surface (Häkkinen 2012), would also be involved (Kühnle et al. 2002) since the authors reported that Cys was adsorbed as dimers and no isolated molecules were found.

These stereosurface complexes presented a controlled orientation with the selected Cys enantiomer; also, a selectivity was observed when a mixture was used, the dimerization being L-L, D-D, according to STM images, Figure 9, bottom (Kühnle et al. 2002). The bridge adsorption was evidenced by the thermoactivated dissolution of four $\mathrm{Au}$ atoms/dimer (Kühnle et al. 2002, 2006a, b). Also, the preference for the [1-10] direction for the formation of this complex (Kühnle et al. 2002, 2006) and even for clusters (Kühnle et al. 2003) was highlighted. Kuhnle at al. (2006) studied the adsorption of L/D-Cys onto surfaces presenting stereoisomeric kinks. This experiment made it possible to observe the preference of D-Cys for $S$-kinks and L-Cys for $R$-kinks, corroborating the idea of stereoselective adsorption. A stereoselective
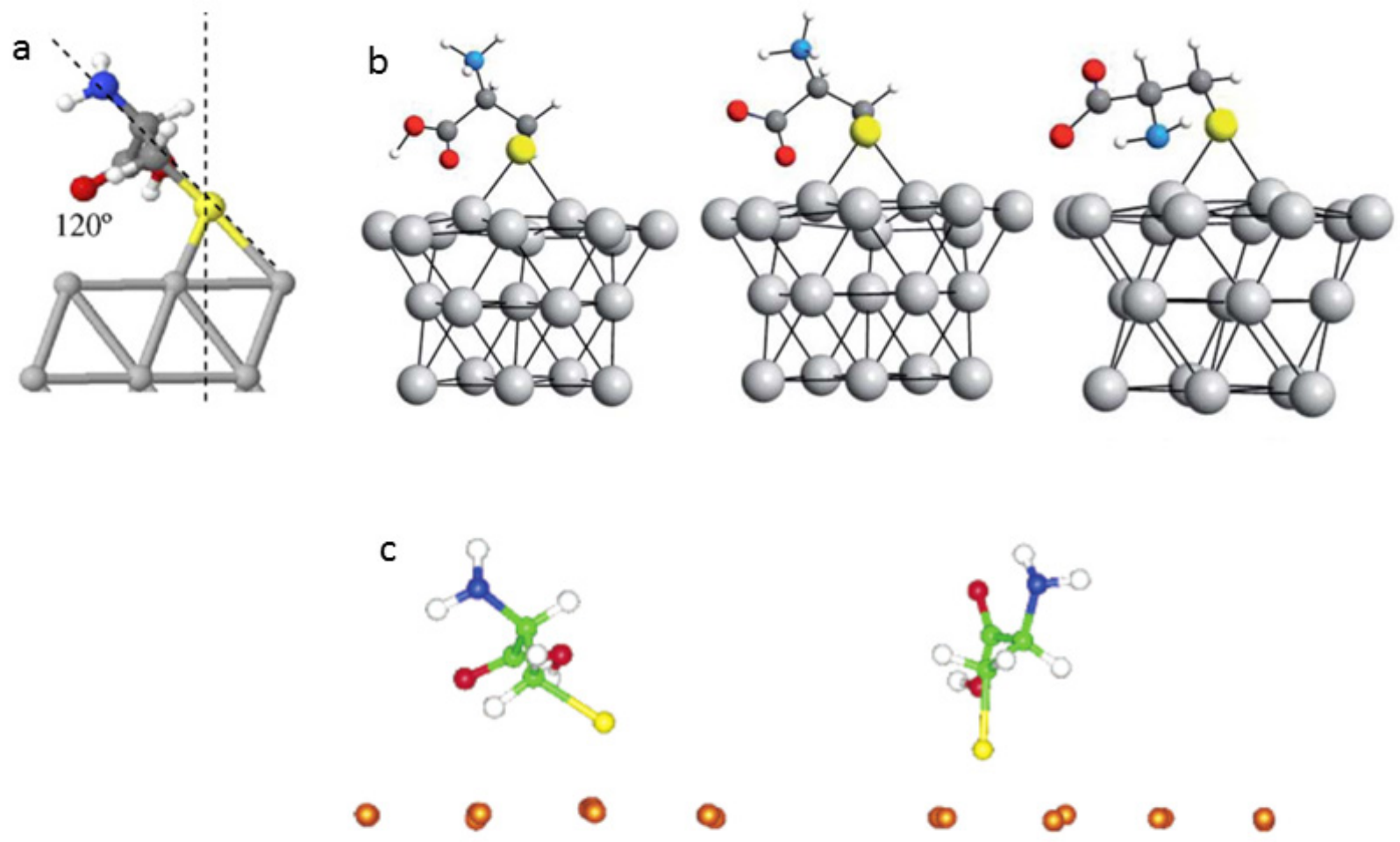

Figure 8 - L-Cys adsorbed structures onto a: Ag (111), adapted from (Santos et al. 2008), b. Pt (111) at acidic, neutral and alkaline media, adapted from (Dourado et al. 2017) and Au (111), adapted from (Di Felice et al. 2003). 

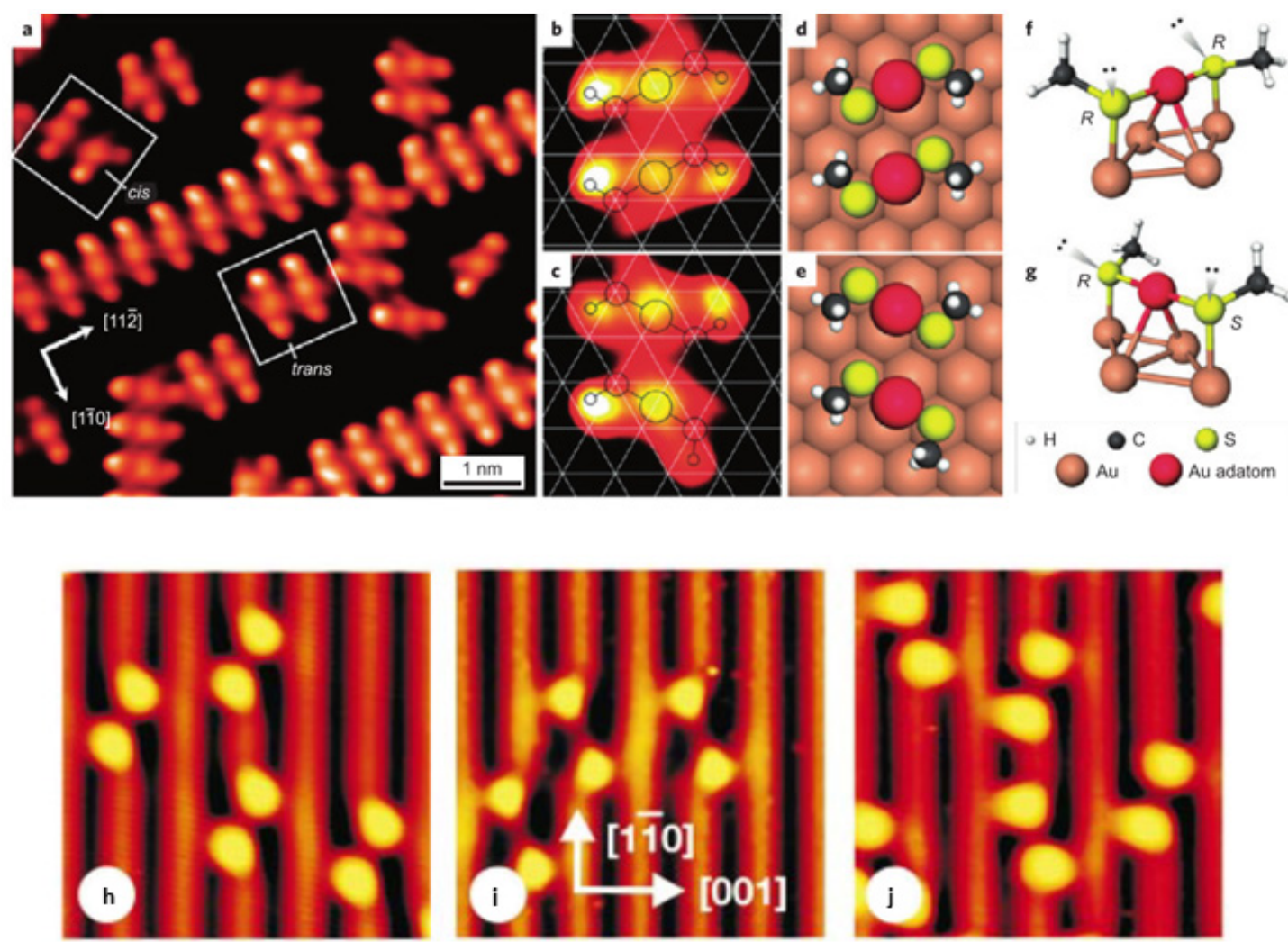

Figure 9 - Selective adsorption of thiols onto Au (111)(a-g), adapted from (Häkkinen 2012) and Cys case, being h the adsorbed dimer for L-Cys, $\mathbf{i}$ for D-Cys and $\mathbf{j}$ the dimers for a racemic starting mixture, adapted from (Kühnle et al. 2002).

self-assembling behavior of Cys adsorption was also suggested for Ag electrodes (Graff and Bukowska 2005) because it was observed that the adsorption of a racemic mixture of Cys presented an adsorption selectivity of the stereoisomer that nucleated the SAM and blocked the adsorption of the other isomer.

The dissolution of four $\mathrm{Au}$ atoms (Kühnle et al. 2002, 2003, 2006a, b) can be explained by the shift of the equilibrium between $\mathrm{Au}(0)$-thiyl/Au(I)thiolate (Reimers et al. 2016), making the latter more favorable.

Chi et al. (2017) reported that the most interesting thiols for electrochemical applications and for surface modifications are the ones presenting the sulfhydryl group at one end of the chain and another function at the other end, usually a function allowing a bond of another molecule of interest. In the case of protein immobilization, a carboxyl or an amine group results, and this is the reason for the use of cysteamine, mercaptopropionic acid, L-Cys and homocysteine for this purpose. Also, as already reported in previous publications (Brolo et al. 2002, Hager and Brolo 2003), the high stability of these SAMs is also related to the hydrogen bond network formed by these functional groups. Also, studies performed with other metals, even single crystals, such as Ag (Luque et al. 2012, Luque and Santos 2012) and $\mathrm{Cu}$ (Marti et al. 2004), showed that the L-Cys adsorbed structure is similar.

Platinum single crystal surfaces are not frequently found in the literature probably because of the low affinity of the sulfhydryl group for this metal, as it is a "hard" acid (Pearson 1963). Also, experimental results and theoretical predictions showed that the structure observed on Pt is different than that observed for "softer" materials (Dourado et al. 2017). Because of this, one can predict that 
the assembling and crystallographic structure of the SAM on Pt should be different since the acidic group is closer to the surface due to the affinity of the Pt surface to "hard" species, such as $\mathrm{H}$, leading to the $\mathrm{H}$ bond of the carboxylic group with the surface in strongly acidic media. The structure is also pH dependent, (Dourado et al. 2017), in a similar way observed for thiol adsorption (Xue et al. 2014). The increasing of $\mathrm{pH}$ changes not just the coverage degree but also its conformation, as already observed for Ag electrodes with potential perturbation (Brolo et al. 2002). Since the carboxyl group is closer to the Pt surface (Dourado et al. $2017)$ and its very acid $\mathrm{H}\left(\mathrm{pKa}_{1}=1.71\right.$ (Hager and Brolo 2009) responsible for the hydrogen bond is not more available, the adsorbed molecule can easily interact with others, probably making the SAM more compact and changing the 2D unit cell as pointed out for different $2 \mathrm{D}$ arrangement on $\mathrm{Au}$ (Chi et al. 2017).

As exposed, the adsorption of L-Cys strongly depends on the surface structure and mainly crystallographic facets. A promising area in chemistry is the use of controlled facets nanoparticles (Lee et al. 2010); so, it is of great interest to place attention on this wide area since this knowledge would make it possible to chemically synthesize materials with high area and controlled crystallography.

\section{CRYSTALLOGRAPHIC CONTROLLED NANOPARTICLES}

The synthesis of controlled shape nanoparticles is very promising for catalysis and sensing applications since the shape is determinant of surface conditions related to surface energy and electronic structure and directly related to their physical and chemical properties (Burda et al. 2005). For the synthesis of nanoparticles, much care related to their cleaning and stabilizing agent is needed since changes in these conditions will affect the final structure and, consequently, the reactivity.

The synthesis of metallic nanoparticles, especially gold (Woźniak-Budych et al. 2016), palladium (Zheng et al. 2015), silver (Wang et al. 2014) and platinum (Lin et al. 2006), is widely studied, and it is possible to obtain sizes from $10 \mathrm{~nm}$ with well-defined structure. The use of these controlled materials is interesting for the possibility of controlling the interaction between the surface and target molecules for catalysis and/ or sensing, as shown for L-Cys (Kühnle et al. 2002, Wackerbarth et al. 2004, Zhang et al. 2011). Nowadays, the search for alternatives to noble metals has allowed the synthesis of controlled reactivity nanoparticles of low-cost species, such as metal oxides. Depending on whether the surface preferential structure is (111), (100) or (110) facets, it affects the chemical reactivity of each one related to the higher surface contribution of $\mathrm{O}$ or $\mathrm{M}$ atomic sites, provoking a higher negative or positive superficial charge density.

For controlling the growth of each single crystalline surface, it is necessary to use a capping agent (CA), a species that adsorbs onto the growing surfaces and stabilizes, preferentially, a specific crystalline facet (Yang et al. 2008, Zhang et al. 2008, 2013). The use of CAs allows the synthesis of a large range of structures with selected facets and for a large range of oxides, among them cuprous oxide $\left(\mathrm{Cu}_{2} \mathrm{O}\right)$, a material of high interest because of their selective response for non-enzymatic sensors and general catalytic applications (Xu and Xue 2007). First, $\mathrm{Cu}_{2} \mathrm{O}$ is a mineral that crystallizes in a cubic structure, where each $\mathrm{Cu}$ atom is neighbored by two $\mathrm{O}$ atoms according to the model of the unit cell (Xu and Xue 2007). For the low-index facets of $\mathrm{Cu}_{2} \mathrm{O}$ crystals, the energy surface is directly related to the number of $\mathrm{Cu}$ atoms coordinated with the surface. In the $\{100\}$ facet, it is possible to observe a clear distribution of $\mathrm{Cu}$ and $\mathrm{O}$ atoms in the crystalline cell, with $\mathrm{O}$ atoms as terminally 

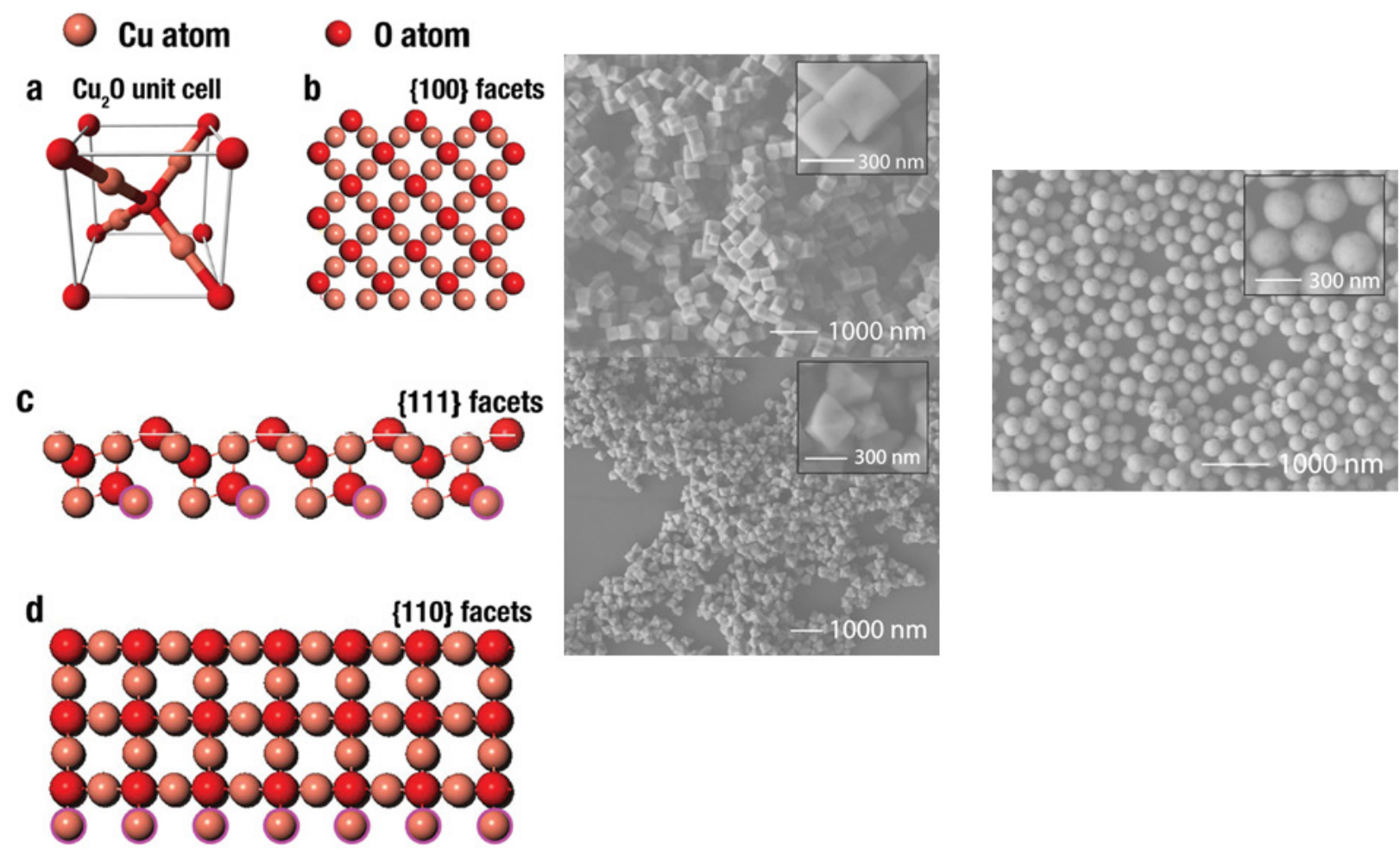

Figure 10 - Model of the unit cells for single crystalline surfaces of $\mathrm{Cu}_{2} \mathrm{O}$ adapted from (Shang and Guo 2015) and SEM figures obtained from the synthesis of cubes (100), octahedral (111) and spheres (110) using SDS as CA and hydroxylamine as reductant agent.

exposed; this distribution generates a neutral surface in the $\{100\}$ facet. On the contrary, $\mathrm{Cu}$ atoms at the $\{111\}$ facet are unsaturated coordinated; each two $\mathrm{Cu}$ atoms there are a dangling bond perpendicular, which makes them positively charged at the surface. The analogous case occurs with the $\{110\}$ facet that presents the same terminated $\mathrm{Cu}$ atoms, as the number of dangling $\mathrm{Cu}$ atoms on the $\{110\}$ plane per unit surface area is approximately 1.5 times higher than on the $\{111\}$ facet (Huang et al. 2012). So, the $\{110\}$ facet should be more positively charged than the $\{111\}$ facet, and the $\{100\}$ would be the less positive one. A commonly used $\mathrm{CA}$ in the synthesis of $\mathrm{Cu}_{2} \mathrm{O}$ nanoparticles is polyvinylpyrrolidone (PVP), which stabilizes the faces with the (111) index (Zhang et al. 2009). The selectivity for this face by this CA is understood by the coulombic attraction of the oxygen atom negatively charged in the carboxyl group of PVP by the positively charged $\mathrm{Cu}$ atoms, which are more exposed in this facet, and the nanoparticle will grow in an octahedral form. Depending on the PVP concentration, the relationship between the $\{111\}$ and $\{100\}$ facets varies, with a greater concentration of PVP favoring the growth of the $\{111\}$ face. It is not possible for the $\{110\}$ facet to obtain with this CA because the adsorption of PVP is not strong enough to create this crystallographic face; therefore, the growth rate is reduced in relation to the other ones. In another similar case, Liang et al. (2009) used oleic acid as the CA, observing stronger adsorption in the rhombic dodecahedron $\mathrm{Cu}_{2} \mathrm{O}$ face, leading to the preferential growth of the 110 face. Another widely used CA is sodium dodecyl sulfate (SDS), which enables the formation of welldefined cubic, spherical and octahedral structures, as shown in Figure 10. The optimization of the amounts of CA - hydroxylamine hydrochloride 
used as reducing agent and $\mathrm{pH}$ control - increases the growth of preferential facets; low pHs lead to the formation of mainly octahedral $\{111\}$ and less reducing agents into mainly cubic structures $\{100\}$.

\section{AMINO ACID INTERACTION WITH CU,}

Despite the use of polycrystalline faces, Dong and co-workers (2008) performed a study in which they used $\mathrm{Cu}_{2} \mathrm{O}$ to modify carbon nanotubes, whereby a composite material was used as a detector for amino acid quantification. In this work, the authors tested 19 amino acids. During voltammetric measurement, the authors verified that the form of the current-potential curves was not dependent on the amino acid used; every procedure for any molecule presented a reversible pair of peaks in the 0.6 - $0.8 \mathrm{~V}$ (vs. SCE) range (Dong et al. 2008). This leads to the conclusion that in the case of the $\mathrm{Cu}_{2} \mathrm{O}$ modified electrode, $\mathrm{CuO}$, the product of $\mathrm{Cu}_{2} \mathrm{O}$ oxidation, is responsible for the electro-oxidation of the amino acids, so the mechanism cannot be dependent on the nature of the amino acid, as they observed (Dong et al. 2008).

One can observe that in Figure 11, the functionalities that are related to the oxidation of the molecule are the carboxylic acid and the amine, so any amino acid can be electrochemically oxidized by this electrode, and this explains why 19 amino acids presented the same reactivity. An interesting observation was the $\mathrm{pH}$ dependence of the electrochemical response of the amino acids (Dong et al. 2008). In the acid media, all amino acids presented the highest activity at $\mathrm{pH}$ values around the isoelectric point of each species, and the reaction was due to single-step oxidation, while the reverse reaction was the $\mathrm{CuO}$ reduction back to $\mathrm{Cu}_{2} \mathrm{O}$. A different behavior was observed at $\mathrm{pH}>11$, where a more complex mechanism was suggested, Figure 11, reactions 7.1-3.

The difference in strong alkaline media was explained by the formation of a new oxidized species, $\mathrm{Cu}$ (III) (Dong et al. 2008). So the reverse reactions, in this case, are the reduction of $\mathrm{CuO}$ to $\mathrm{Cu}_{2} \mathrm{O}$ and $\mathrm{CuOOH}$ to $\mathrm{CuO}$ or $\mathrm{Cu}_{2} \mathrm{O}$, but no more details about this behavior were presented in this publication. A similar mechanism can be expected for glucose and carbohydrates, generalized in Figure 11, reaction 7.4 (Alizadeh and Mirzagholipur 2014), in which $\mathrm{CuOOH}$ is reduced to $\mathrm{CuO}$ by a single oxidation of the molecule. After that, $\mathrm{CuO}$ can be reduced once more to $\mathrm{Cu}_{2} \mathrm{O}$ by the oxidation of another molecule or functionality, as shown in reactions 7.1-3. So, the complexity of the oxidation at $\mathrm{pH}>11$ is not just related to the greater amount of possible paths $-7.1-3$ could also take place of $\mathrm{CuO}$ being reduced to $\mathrm{Cu}_{2} \mathrm{O}-$ but also to additional possible oxidizing leading to different steps.

Some reports used shaped controlled nanoparticles (Maity et al. 2014, Zhang et al. 2008), prepared by using PVP as CA (Zhang et al. 2008). Authors studied L-Trp (Maity et al. 2014) L-Tyr (Zhang et al. 2008) interaction with the (111) face. It was observed that the amine groups are responsible for the bonding of the L-Trp because the bands in FTIR spectra related to $-\mathrm{NH}_{2}$ modes were shifted (Maity et al. 2014). In the case of L-Tyr (Zhang et al. 2008), impedance measurements were performed, and Nyquist plots were interpreted as an indication of the amino acid adsorption, and octahedra were found to be more electroactive than spherical nanoparticles. The discussion about why this specific form was the most active, presenting the highest currents, is still open.

Dong etal.(2008) evaluated the electrochemical response of many amino acids, and they noted that the oxidation of the L-Tyr should follow the mechanism related to Figure 11, but in neutral media, $\mathrm{CuO}$ was the oxidant agent. A comparison with Zhang et al. (2008) shows that the oxidation peaks are not in the same region; for octahedra, they were shifted to more negative potentials. This fact can be explained by the facet reactivity, as shown in the previous section; it is expected to vary 


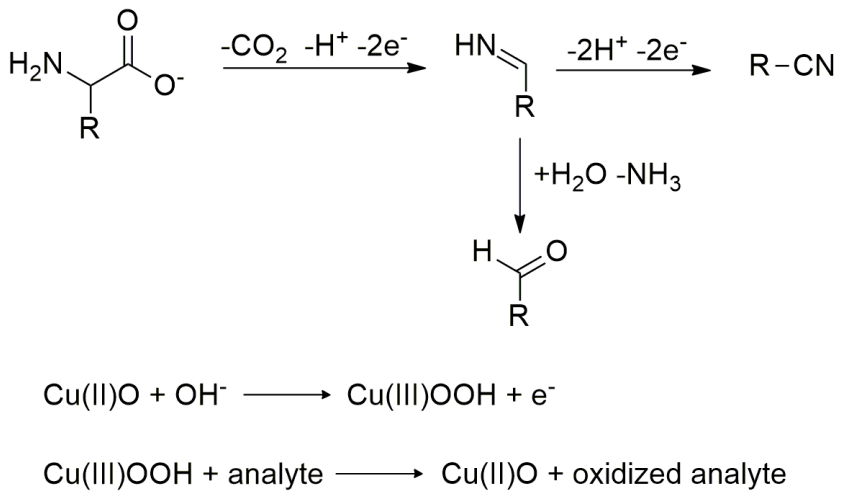

Figure 11 - Oxidation of amino acids onto $\mathrm{Cu}_{2} \mathrm{O}$ nanoparticles by 7.1(Dong et al. 2008) and 7.2 (Alizadeh and Mirzagholipur 2014).

with the crystallographic orientation, and so the $\mathrm{CuO}$ generation is more favorable to this positively charged surface. The adsorption of both amino acids can be due to the $-\mathrm{NH}_{2}$, but for L-Tyr, there is the possibility of it being due to the phenol moiety, but the authors did not go further with spectroscopic measurements to verify this hypothesis (Zhang et al. 2008).

The positively charged $\mathrm{Cu}$ atoms on the (111) facet are also responsible for the immobilization of thiols onto this kind of surface, as shown by Azimi et al. (2014) in their work about the immobilization of mercaptopropionic acid on $\mathrm{Cu}_{2} \mathrm{O}$ nanoparticles. $\mathrm{Cu}$ is also a "soft" acid (Pearson 1963), just as Au is, but since it is not as polarizable as the latter, the interaction between the thiol and $\mathrm{Cu}$ is expected to present an ionic character, since $\mathrm{Cu}$ is "harder" than Au. Azimi et al. (2014), based on XPS experiments, were able to verify that the adsorption was due to the thiol, corroborating information obtained by FTIR experiments. $\mathrm{Cu}_{2} \mathrm{O}$ presents a band at 615 $\mathrm{cm}^{-1}$ related to the $\mathrm{Cu}-\mathrm{O}$ stretch, observed before and after the modification of the nanoparticles. But, after the modification, the intensification and enlargement of this band, probably due to C-S stretch, is expected to be in this region for $\mathrm{Pt}$ (Dourado et al. 2017), Ag (Brolo et al. 2002) and Au (Anema and Brolo 2010). The XPS measurements also verify that the thiol was in its thiolate form and
$\mathrm{Cu}$ was locally reduced to $\mathrm{Cu}^{0}$ (Azimi et al. 2014), making it possible to observe the same equilibrium observed for thiols adsorbed onto Au.

The thiol function, since it is adsorbed by the sulfur atom, is probably oxidized by a mechanism different from the one presented by reactions 7.13 ; it is most likely oxidized to sulfonic acid as presented in Figure 5 but in a more simple pathway than that presented in Figure 6, similar to reactions 7.4-6 for alkaline media. At the moment, no more data clarifying these facts can be found indicating that the subject is still open to further study.

The bonding between the thiol and the $\mathrm{Cu}$ atoms can also be used for the synthesis of well-orientated crystallographic faces in a nonthermodynamic favorable way (Choe et al. 2007, Dai et al. 2005). For this kind of approach, a DNA binding protein was used as a template for the growing of the nanoparticles. This approach has been used for different crystallographic arrays not observed in traditional synthesis (Okuda et al. 2012). Since the use of proteins as templates is possible for nanoparticle synthesis, the relation between the amino acids and these nanoparticles is a subject that needs to be elucidated. The $\mathrm{Cu}_{2} \mathrm{O}$ synthesis by protein template (Choe et al. 2007, Dai et al. 2005) was only possible because the protein of interest was modified and some L-Cys residues, responsible for the immobilization of the growing 
particle inside the protein, allow the process to take place in non-thermodynamic favorable conditions.

\section{CONCLUSIONS}

The electrochemistry of proteins is an important tool for diagnosis, not just for redox enzymes but also for the ones that do not present this behavior in vivo. The presence or absence of the electroactive amino acids (L-Tyr, L-Trp, L-His, L-Met, and L-Cys) orientated to the outside of the protein structures can give important information about the structure of the (poly)peptide since the potential window observed for each one is the same for the free and bonded residues. The study of the electrochemical activity of these molecules is not new but still remains open for discussion, and the most recent efforts in this field can be summarized in Table I.

The sulfur-containing amino acids, L-Met and L-Cys, are the most interesting for study since not just the proteomic application is important; it can also help the understanding of the redox behavior of any protein. Also, L-Cys seems to be the most interesting example of the group since it can also be used as a surface modifier, allowing the binding of other molecules, especially proteins. This modification of the surface is of great interest also for regular thiols and is the object of study of many groups, allowing the discovery that the relation of the simplest thiol is stereoselective. So, it was expected and observed that Cys adsorption is also an interesting tool for surface engineering.

For this modification, one can also keep in mind that adsorption of the thiol onto metallic surfaces is described by an equilibrium between $\mathrm{M}(0)$-Thiyl and $\mathrm{M}(\mathrm{I})$-Thiolate, and the use of different conditions can make one side or the other more stable, being the last one responsible for the corrosion of the surface.

For surface engineering, the crystallographic facet exposed is of high interest, and due to the limitations of disponibilization in the large scale of noble metals, the use of well-defined metal oxide nanostructures is of high interest, especially $\mathrm{Cu}_{2} \mathrm{O}$. The well-defined nanoparticles of the synthesis is facilitated by the use of CA, as PVP or SDS, allowing the chemical synthesis of cubes (100), octahedra (111) and (110) structures to keep the process fast and simple.

For those structures, all amino acids seemed to be active since the electrochemistry is ruled by the disponibilization of $\mathrm{CuO}$ and $\mathrm{CuOOH}$, but L-Cys was once more observed to be different from the others since the acid-base reaction responsible for its adsorption is able to modify the surface with this molecule and to use this residue as a tool to anchor growing crystals in bio templates for nonthermodynamic-favorable structures.

TABLE I

The most recent efforts in the study of electroactive amino acids.

\begin{tabular}{|c|c|c|}
\hline $\begin{array}{c}\text { Amino } \\
\text { acid }\end{array}$ & Important advance & Reference \\
\hline L-Trp & $\begin{array}{l}\text { Mechanistic evaluation } \\
\text { onto Carbon electrodes }\end{array}$ & $\begin{array}{c}\text { (Enache and } \\
\text { Oliveira-Brett } \\
\text { 2011a) }\end{array}$ \\
\hline \multirow[b]{2}{*}{ L-Tyr } & $\begin{array}{l}\text { Mechanistic evaluation } \\
\text { onto Carbon electrodes }\end{array}$ & $\begin{array}{l}\text { (Enache and } \\
\text { Oliveira-Brett } \\
\text { 2011b) }\end{array}$ \\
\hline & $\begin{array}{l}\text { Comparison between } \\
\text { bonded and not bonded } \\
\text { molecule }\end{array}$ & $\begin{array}{c}\text { (Enache and } \\
\text { Oliveira-Brett 2017) }\end{array}$ \\
\hline L-Met & $\begin{array}{l}\text { Comparison between } \\
\text { bonded and not bonded } \\
\text { molecule }\end{array}$ & $\begin{array}{c}\text { (Enache and } \\
\text { Oliveira-Brett 2017) }\end{array}$ \\
\hline L-His & $\begin{array}{l}\text { Mechanistic evaluation } \\
\text { onto diamond electrodes }\end{array}$ & (Chen et al. 2008) \\
\hline \multirow{3}{*}{ L-Cys } & $\begin{array}{l}\text { Mechanistic evaluation } \\
\text { onto diamond electrodes }\end{array}$ & $\begin{array}{c}\text { (Enache and } \\
\text { Oliveira-Brett 2011) }\end{array}$ \\
\hline & $\begin{array}{l}\text { Mechanistic evaluation } \\
\text { onto Pt electrodes }\end{array}$ & $\begin{array}{c}\text { (Dourado et al. 2017, } \\
2016)\end{array}$ \\
\hline & $\begin{array}{c}\text { Adsorption onto Ag } \\
\text { surfaces, theoretical } \\
\text { studies }\end{array}$ & $\begin{array}{l}\text { (Luque et al. 2012, } \\
\text { Luque and Santos } \\
\text { 2012) }\end{array}$ \\
\hline
\end{tabular}




\section{ACKNOWLEDGMENTS}

The authors would like to thank Conselho Nacional de Desenvolvimento Científico e Tecnológico (CNPq) and Fundação de Amparo a Pesquisa do Estado de São Paulo (FAPESP) 2015/26308-7. A.H.B.D. thanks, FAPESP (2013/25592-8) and Coordenação de Aperfeiçoamento de Pessoal de Nível Superior (CAPES) for the scholarships granted.

\section{REFERENCES}

ALIZADEH T AND MIRZAGHOLIPUR S. 2014. A Nafionfree non-enzymatic amperometric glucose sensor based on copper oxide nanoparticles-graphene nanocomposite. Sens Actuator B-Chem 198: 438-447.

ANEMA JR AND BROLO AG. 2010. Use of polarizationdependent SERS from scratched gold films to monitor the electrochemically-driven desorption and readsorption of cysteine. J Electroanal Chem 649(1-2): 159-163.

AZIMI H ET AL. 2014. Effective Ligand Passivation of $\mathrm{Cu}$ 2 O Nanoparticles through Solid-State Treatment with Mercaptopropionic Acid. J Am Chem Soc 136(20): 72337236.

BIERI M AND BÜRGI T. 2005. Adsorption kinetics, orientation, and self-assembling of N-acetyl-L-cysteine on gold: A combined ATR-IR, PM-IRRAS, and QCM study. J Phys Chem B 109(47): 22476-22485.

BRDIČKA R. 1933.Polarographic studies with the dropping mercury kathode. Part XXXI. A new test for proteins in the presence of cobalt salts in ammoniacal solutions of ammonium chloride. Collect Czech Chem Comm 5: 112128.

BROLO AG, GERMAIN P AND HAGER G. 2002. Investigation of the Adsorption of 1-Cysteine on a Polycrystalline Silver Electrode by Surface-Enhanced Raman Scattering (SERS) and Surface-Enhanced Second Harmonic Generation (SESHG). J Phys Chem B 106(23): 5982-5987.

BURDA C, CHEN X, NARAYANAN R AND EL-SAYED MA. 2005. Chemistry and Properties of Nanocrystals of Different Shapes. J Am Chem Soc 105: 1025-1102.

CAI X, RIVAS G, FARIAS PAM, SHIRAISHI H, WANG J AND PALEČEK. 1996. Potentiometric stripping analysis of bioactive peptides at carbon electrodes down to subnanomolar concentrations. Anal Chim Acta 332(1): 4957.

CHEN L, CHANG C AND CHANG H. 2008. Electrochemical oxidation of histidine at an anodic oxidized boron-doped diamond electrode in neutral solution. Electrochim Acta 53(6): 2883-2889.

CHI Q, FORD MJ, HALDER A, HUSH NS, REIMERS JR AND ULSTRUP J.2017. Sulfur ligand mediated electrochemistry of gold surfaces and nanoparticles: What, how, and why. Curr Opin Electrochem 1(1): 7-15.

CHOE WSS, SASTRY MSR, THAI CK, DAI H, SCHWARTZ DT AND BANEYX F. 2007. Conformational control of inorganic adhesion in a designer protein engineered for cuprous oxide binding. Langmuir 23(23): 11347-11350.

COSTA D, PRADIER CM, TIELENS F AND SAVIO L. 2015. Adsorption and self-assembly of bio-organic molecules at model surfaces: A route towards increased complexity. Surf Sci Rep 70(4): 449-453.

CUNNINGHAM S, GERLACH JQ, KANE M AND JOSHI L. 2010. Glyco-biosensors: recent advances and applications for the detection of free and bound carbohydrates. Analyst 135(10): 2471-2480.

DAI H, CHOE WS, THAI CK, SARIKAYAM, TRAXLER BA, BANEYX F AND SCHWARTZ DT. 2005. Nonequilibrium synthesis and assembly of hybrid inorganic-protein nanostructures using an engineered DNA binding protein. J Am Chem Soc 127(44): 15637-15643.

DAVIS DG AND BIANCO E. 1996. An Electrochemical Study of the Oxidation of L-Cysteine. J Electroanal Chem 12: 254-260.

DI FELICE R AND SELLONI A. 2004. Adsorption modes of cysteine on $\mathrm{Au}(111)$ : thiolate, amino-thiolate, disulfide. J Chem Phys 120(10): 4906-4914.

DI FELICE R, SELLONI A AND MOLINARI E. 2003. DFT Study of Cysteine Adsorption on Au (111). J Phys Chem B 107(111): 1151-1156.

DONG S, ZHANG S, CHI L, HE P, WANG Q AND FANG Y. 2008. Electrochemical behaviors of amino acids at multiwall carbon nanotubes and $\mathrm{Cu} 2 \mathrm{O}$ modified carbon paste electrode. Anal Biochem 381(2): 199-204.

DOURADO AHB ET AL. 2016. Investigation of the electrochemical behavior of 1-cysteine in acidic media. J Electroanal Chem 765: 87-91.

DOURADO AHB ET AL. 2017. 1 -Cysteine electrooxidation in alkaline and acidic media: a combined spectroelectrochemical and computational study. RSC Adv 7(13): 7492-7501.

ENACHE TA, CHIORCEA-PAQUIM AM AND OLIVEIRABRETT AM. 2016. Amyloid- $\beta$ peptides time-dependent structural modifications: AFM and voltammetric characterization. Anal Chim Acta 926: 36-47.

ENACHE TAAND OLIVEIRA-BRETT AM. 2011a. Pathways of Electrochemical Oxidation of Indolic Compounds. Electroanal 23(6): 1337-1344.

ENACHE TA AND OLIVEIRA-BRETT AM. 2011b. Phenol and para-substituted phenols electrochemical oxidation pathways. J Electroanal Chem 655(1): 9-16. 
ENACHE TA AND OLIVEIRA-BRETT AM. 2011c. Boron doped diamond and glassy carbon electrodes comparative study of the oxidation behaviour of cysteine and methionine. Bioelectrochem 81(1): 46-52.

ENACHE TA AND OLIVEIRA-BRETT AM. 2013. Peptide methionine sulfoxide reductase A (MsrA): Direct electrochemical oxidation on carbon electrodes. Bioelectrochem 89: 11-18.

ENACHE TA AND OLIVEIRA-BRETT AM. 2017. Bioelectrochemistry Alzheimer>s disease amyloid beta peptides in vitro electrochemical oxidation. Bioelectrochem 114: 13-23.

EU S AND PAIK WK. 1999. Self-Assembly Process of Organosulfur Molecular Layers on Gold: Electrochemical Mechanisms. Mol Cryst Liq Cryst Sci Technol Sect A 337: 39-52.

FELICIANO-RAMOS I CABAN-ACEVEDO M, SCIBIOH MA AND CABRERA CR. 2010. Self-assembled monolayers of 1-cysteine on palladium electrodes. J Electroanal Chem 650(1): 98-104.

GERLACH JQ ET AL. 2010. Glycobiomimics and glycobiosensors. Biochem Soc Trans 38(5): 1333-1336.

GRAFF M AND BUKOWSKA J. 2005. Adsorption of enantiomeric and racemic cysteine on a silver electrode SERS sensitivity to chirality of adsorbed molecules. J Phys Chem B 109(19): 9567-9574.

HAGER G AND BROLO AG. 2003. Adsorption/desorption behaviour of cysteine and cystine in neutral and basic media: electrochemical evidence for differing thiol and disulfide adsorption to a $\mathrm{Au}(111)$ single crystal electrode. J Electroanal Chem 550-551: 291-301.

HAGER G AND BROLO AG. 2009. Protonation and deprotonation of cysteine and cystine monolayers probed by impedance spectroscopy. J Electroanal Chem 625(2): 109-116.

HÄKKINEN H. 2012. The gold-sulfur interface at the nanoscale. Nat Chem 4(6): 443-455.

HEYROVSKÝ J AND BABIČKA J. 1930. Polarographic studies with the dropping mercury kathode. Part XIII. The effect of albumins. Collect Czech Chem Commun 2: 370379.

HUANG WC, LYU LM, YANG YC AND HUANG MH. 2012. Synthesis of $\mathrm{Cu}_{2} \mathrm{O}$ nanocrystals from cubic to rhombic dodecahedral structures and their comparative photocatalytic activity. J Am Chem Soc 134(2): 12611267.

JACOB C, GILES GI, GILES NM AND SIES H. 2003. Sulfur and Selenium: The Role of Oxidation State in Protein Structure and Function. Angew Chem Int Ed 42(39): 47424758.

JOHLL ME, WILLIAMS DG AND JOHNSON DC. 1997. Activated pulsed amperometric detection of cysteine at platinum electrodes in acidic media. Electroanal 9(18): 1397-1402.

JURKA E. 1939. Polarographic studies with the dropping mercury kathode. Part LXXIX. Investigation of the simultaneous occurrence of the two known protein effects produced in buffered cobalt solutions. Collect Czech Chem Commun 11: 243-255.

KORYTA J AND PRADAC J. 1968a. Electrode Process of the Sulfhydryl-Disulfide System II. Cysteine at a Gold Electrode. J Electroanal Chem Interfacial Electrochem 17: 177-183.

KORYTA J AND PRADAC J. 1968b. Electrode Process of the Sulfhydryl-Disulfide System III. Cysteine at Platinum and Gold Electrodes. J Electroanal Chem Interfacial Electrochem 17: 185-189.

KÜHNLE A, LINDEROTH TR AND BESENBACHER F. 2003. Self-assembly of monodispersed, chiral nanoclusters of cysteine on the Au(110)-(1 x 2) surface. J Am Chem Soc 125(48): 14680-14681.

KÜHNLE A, LINDEROTH TR AND BESENBACHER F. 2006. Enantiospecific adsorption of cysteine at chiral kink sites on $\mathrm{Au}(110)-(1 \mathrm{x} 2)$. J Am Chem Soc 128(4): 10761077.

KÜHNLE A, LINDEROTH TR, HAMMER B AND BESENBACHER F. 2002. Chiral recognition in dimerization of adsorbed cysteine observed by scanning tunnelling microscopy. Nature 415(6874): 891-893.

KÜHNLE A, LINDEROTH TR, SCHUNACK M AND BESENBACHER F. 2006. L-cysteine adsorption structures on $\mathrm{Au}(111)$ investigated by scanning tunneling microscopy under ultrahigh vacuum conditions. Langmuir 22(5): 2156-2160.

LEE K, KIM M AND KIM H. 2010. Catalytic nanoparticles being facet-controlled. J Mater Chem 20(19): 3791-3837.

LEY C, HOLTMANN D, MANGOLD KM AND SCHRADER J. 2011. Immobilization of histidine-tagged proteins on electrodes. Colloids Surf B 88(2): 539-551.

LIANG X et al. 2009. Facile Synthesis and Shape Evolution of Single-Crystal Cuprous Oxide. Adv Mater 21(20): 20682071.

LIN CS, KHAN MR AND LIN SD. 2006. The preparation of Pt nanoparticles by methanol and citrate. J Colloid Interface Sci 299(2): 678-685.

LUQUE NB AND SANTOS E. 2012. Ab Initio Studies of Ag - S Bond Formation during the Adsorption of L-Cysteine on Ag (111). Langmuir 28(111): 11472-11480.

LUQUE NB, VÉLEZ P, PÖTTING K AND SANTOS E. 2012. $\mathrm{Ab}$ Initio Studies of the Electronic Structure of L-Cysteine Adsorbed on Ag (111). Langmuir 28(111): 8084-8099.

MAITY M, PRAMANIK SK, PAL U, BANERJI B AND MAITI NC. 2014. Copper(I) oxide nanoparticle and tryptophan as its biological conjugate: A modulation of cytotoxic effects. J Nanopart Res 16(1): 2179. 
MALFOY B AND REYNAUD JA. 1980. Electrochemical investigations of amino acids at solid electrodes. J Electroanal Chem Interfacial Electrochem 114(2): 213223.

MARTI EM, METHIVIER C AND PRADIER CM. 2004. (S)cysteine chemisorption on $\mathrm{Cu}(110)$, from the gas or liquid phase: an FT-RAIRS and XPS study. Langmuir 20(110): 10223.

MINEVICH I AND TUR'YAN YI. 2013. Application of the modified polarographic Brdička method for cancer testing. J Solid State Electrochem 17(6): 1529-1533.

NAZMUTDINOV RR, ZHANG J, ZINKICHEVA TT, MANYUROV IR AND ULSTRUP J. 2006. Adsorption and in situ scanning tunneling microscopy of cysteine on $\mathrm{Au}(111)$ : Structure, energy, and tunneling contrasts. Langmuir 22(18): 7556-7567.

OGURA K, KOBAYASHI M, NAKAYAMA M AND MIHO Y. 1999. In-situ FTIR studies on the electrochemical oxidation of histidine and tyrosine. J Electroanal Chem 463(2): 218-223.

OKUDA M, ELOI JC, WARD JONES SE, SARUA A, RICHARDSON RM AND SCHWARZACHER W. 2012. Fe3O4 nanoparticles: protein-mediated crystalline magnetic superstructures. Nanotechnology 23(41): 415601.

PAIK WK, EU S, LEE K, CHON S AND KIM M. 2000. Electrochemical Reactions in Adsorption of Organosulfur Molecules on Gold and Silver: Potential Dependent Adsorption. Langmuir 16(26): 10198-10205.

PALEČEK E, TKÁČ J, BARTOŠÍK M, BERTÓK T, OSTATNÁ V AND PALEČEK J. 2015. Electrochemistry of nonconjugated proteins and glycoproteins. Toward sensors for biomedicine and glycomics. Chem Rev 115(5): 2045-2108.

PEARSON G. 1963. Hard and Soft Acids and Bases. J Am Chem Soc 85(22): 3533-3539.

POPOVIĆ ND AND JOHNSON DC. 1998. A Ring-Disk Study of the Competition between Anodic OxygenTransfer and Dioxygen-Evolution Reactions. Anal Chem 70(3): 468-472.

PRADAC J AND KORYTA J. 1968. Electrode Process of The Sulfhydryl-Disulfid System I. Cysteine at Platinum Electrode. J Electroanal Chem Interfacial Electrochem 17: 167-175.

REIMERS JR, FORD MJ, HALDER A, ULSTRUP J, HUSH NS. 2016. Gold surfaces and nanoparticles are protected by $\mathrm{Au}(0)$-thiyl species and are destroyed when $\mathrm{Au}(\mathrm{I})$-thiolates form. Proc Natl Acad Sci U S A 113(11): E1424-33.

REYNAUD JA, MALFOY B AND CANESSON P. 1980 Electrochemical investigations of amino acids at solid electrodes. J Electroanal Chem Interfacial Electrochem 114(2): 195-211.
RON H AND RUBINSTEIN I. 1998. Self-assembled monolayers on oxidized metals. 3. Alkylthiol and dialkyl disulfide assembly on gold under electrochemical conditions. J Am Chem Soc 120(51): 13444-13452.

SAMEC Z, MALYSHEVA ZH, KORYTA J AND PRADÁČ. 1975. A Contribution to the Voltammetric Study of Cysteine and Cystine ar Pt Electrodes in 0.5 M H2SO4. J Electroanal Chem 65: 573-586.

SANTOS E, AVALLE L, PÖTTING K, VÉLEZ P AND JONES H. 2008. Experimental and theoretical studies of 1-cysteine adsorbed at $\mathrm{Ag}(111)$ electrodes. Electrochim Acta 53(23): 6807-6817.

SANTOS E, AVALLE LB, SCURTU R AND JONES H. 2007. 1-Cysteine films on $\mathrm{Ag}(111)$ investigated by electrochemical and nonlinear optical methods. Chem Phys 342(1-3): 236-244.

SUPRUN EV, ZHARKOVA MS, MOROZEVICH GE, VESELOVSKY AV, SHUMYANTSEVA VV AND ARCHAKOV AI. 2013. Analysis of redox activity of proteins on the carbon screen printed electrodes. Electroanal 25(9): 2109-2116.

TIELENS F AND SANTOS E. 2010. AuS and SH bond formation/breaking during the formation of alkanethiol SAMs on Au(111): A theoretical study. J Phys Chem C 114(20): 9444-9452.

TUDOS AJ, VANDEBERG PJ AND JOHNSON DC. 1995. Evaluation of Eqcm Data From a Study of Cysteine Adsorption on Cold Electrodes in Acidic Media. Anal Chem 67(3): 552-556.

VANDEBERG PJ AND JOHNSON DC. 1993. Pulsed electrochemical detection of cysteine, cystine, methionine, and glutathione at gold electrodes following their separation by liquid chromatography. Anal Chem 65(20): 2713-2718.

VIJH AK AND CONWAY BE. 1967. Electrode Kinetic Aspects of the Kolbe Reaction. Chem Rev 67(6): 623-664.

WACKERBARTH H, MARIE R, GRUBB M, ZHANG J, HANSEN AG, CHORKENDORFF I, CHRISTENSEN CBV, BOISEN A AND ULSTRUP J. 2004. Thiol- and disulfide-modified oligonucleotide monolayer structures on polycrystalline and single-crystal $\mathrm{Au}(111)$ surfaces. J Solid State Electrochem 8(7): 474-481.

WANG JL, ANDO RA AND CAMARGO PHC. 2014. Investigating the plasmon-mediated catalytic activity of $\mathrm{AgAu}$ nanoparticles as a function of composition: Are two metals better than one? ACS Catalysis 4(11): 3815-3819.

WANG WH, HIMEDA Y, MUCKERMAN JT, MANBECK GF AND FUJITA E. 2015. CO2 Hydrogenation to Formate and Methanol as an Alternative to Photo- and Electrochemical CO2 Reduction. Chem Rev 115(23): 12936-12973.

WATANABE T AND MAEDA H. 1989. Adsorption-controlled redox activity. Surface-enhanced Raman investigation of 
cystine versus cysteine on silver electrodes. J Phys Chem 93(8): 3258-3260.

WIDRIG CA, CHUNG C AND PORTER MD. 1991. The electrochemical desorption of n-alkanethiol monolayers from polycrystalline $\mathrm{Au}$ and $\mathrm{Ag}$ electrodes. J Electroanal Chem 310(1-2): 335-359.

WOŹNIAK-BUDYCH MJ ET AL. 2016. Copper-gold nanoparticles: Fabrication, characteristic and application as drug carriers. Mater Chem Phys 179: 242-253.

XU JJ, PENG Y, BAO N, XIA XH AND CHEN HY. 2005. Simple method for the separation and detection of native amino acids and the identification of electroactive and non-electroactive analytes. J Chromatogr A 1095(1-2): 193-196.

XU J AND XUE D. 2007. Five branching growth patterns in the cubic crystal system: A direct observation of cuprous oxide microcrystals. Acta Mater 55(7): 2397-2406.

XUE Y, LI X, LI H AND ZHANG W. 2014. Quantifying thiolgold interactions towards the efficient strength control. Nature Commun 5: 4348.

YANG HG, SUN CH, QIAO SZ, ZOU J, LIU G, SMITH SC, CHENG HM AND LU GQ. 2008. Anatase TiO2 single crystals with a large percentage of reactive facets. Nature 453(7195): 638-641.

ZHANG DF, ZHANG H, GUO L. ZHENG K, HAN XD AND ZHANG Z. 2009. Delicate control of crystallographic facet-oriented $\mathrm{Cu} 2 \mathrm{O}$ nanocrystals and the correlated adsorption ability. J Mater Chem 19(29): 5220-5225.

ZHANG J, BILIC A, REIMERS JR, HUSH NS AND ULSTRUP J. 2005. Coexistence of multiple conformations in cysteamine monolayers on $\mathrm{Au}(111)$. J Phys Chem B 109(32):15355-15367.

ZHANG J, CHI Q AND ULSTRUP J. 2006. Assembly dynamics and detailed structure of 1-Propanethiol monolayers on $\mathrm{Au}(111)$ surfaces observed real time by in situ STM. Langmuir 22(14): 6203-6213.
ZHANG J, WELINDER AC, CHI Q AND ULSTRUP J. 2011. Electrochemically controlled self-assembled monolayers characterized with molecular and sub-molecular resolution. Phys Chem Chem Phys 13(13): 5526-5545.

ZHANG X, WANG G, GU A, WU H AND FANG B. 2008. Preparation of porous $\mathrm{Cu} 2 \mathrm{O}$ octahedron and its application as L-Tyrosine sensors. Solid State Commun 148(11-12): 525-528.

ZHANG Z, ZHONG C, DENG Y, LIU L, WU Y AND HU W. 2013. The manufacture of porous cuprous oxide film with photocatalytic properties via an electrochemical-chemical combination method. RSC Advances 3(19): 6763.

ZHENG W ET AL. 2015. Probing the Size and Shape Effects of Cubic- and Spherical-Shaped Palladium Nanoparticles in the Electrooxidation of Formic Acid. ChemCatChem 7(23): 3826-3831.

ZHONG CJ AND PORTER MD. 1997. Fine structure in the voltammetric desorption curves of alkanethiolate monolayers chemisorbed at gold. J Electroanal Chem 425(1-2): 147-153.

ZHONG CJ, ZAK J AND PORTER MD. 1997. Voltammetric reductive desorption characteristics of alkanethiolate monolayers at single crystal $\mathrm{Au}(111)$ and (110) electrode surfaces. J Electroanal Chem 421: 9-13.

ZHOU Y, YU B AND LEVON K. 2004. The role of cysteine residues in electrochemistry of cytochrome $\mathrm{c}$ at a polyaniline modified electrode. Synth Met 142(1-3): 137141.

ZHU S, ZHANG J, ZHAO X, WANG H, XU G AND YOU J. 2014. Electrochemical behavior and voltammetric determination of L-tryptophan and L-tyrosine using a glassy carbon electrode modified with single-walled carbon nanohorns. Microchim Acta 181(3-4): 445-451.

ZINOLA CF, RODRÍGUEZ JL, ARÉVALO MC AND PASTOR E. 2005. FTIR studies of tyrosine oxidation at polycrystalline Pt and Pt( $\left.\begin{array}{lll}1 & 1 & 1\end{array}\right)$ electrodes. J Electroanal Chem 585(2): 230-239. 